\title{
INFLUÊNCIA DO ESPAÇAMENTO ENTRE COLETORES, DO NÚMERO DE LINHAS RADIAIS E DA ALTURA DO EMISSOR NO COEFICIENTE DE UNIFORMIDADE DE CHRISTIANSEN PARA PIVÔ CENTRAL
}

\section{ALEXANDRE BRYAN HEINEMANN}

Engenheiro Agrônomo

Orientador: Prof. Dr. José Antônio Frizzone

Dissertação apresentada à Escola Superior de Agricultura "Luiz de Queiroz", da Universidade de São Paulo, para obtenção do Título de Mestre em Agronomia, Área de Concentração: Irrigação e Drenagem.

PIRACICABA

Estado de São Paulo - Brasil

Agosto de 1996 
Dados Internacionais de Catalogação na Publicação (CIP)

DIVISĀO DE BIBLIOTECA E DOCUMENTAÇĀO - Campus “Luiz de Queiroz"/USP

Heinemann, Alexandre Bryan

Influência do espaçamento entre coletores, do número de linhas radiais e da altura do emissor no coeficiente de uniformidade de Christansen para pivô central / Alexandre Bryan Heinemann. - - Piracicaba, 1996.

64p. : il.

Dissertação (mestrado) - - Escola Superior de Agricultura Luiz de Queiroz, 1996.

Bibliografia.

1. Água de irrigação - Distribuição - Avaliação 2. Coletor - Espaçamento

3. Irrigação por pivô central 4. Modelo matemático I. Título 


\section{INFLUÊNCIA DO ESPAÇAMENTO ENTRE COLETORES, DO NÚMERO DE LINHAS RADIAIS E DA ALTURA DO EMISSOR NO COEFICIENTE DE UNIFORMIDADE DE CHRISTIANSEN PARA PIVÔ CENTRAL}

\section{ALEXANDRE BRYAN HEINEMANN}

Aprovada em: 30/08/96

Comissão julgadora:

Prof. Dr. José Antônio Frizzone

Prof. Dr. Marcos Vinícius Folegatti

Prof. Dr. José Geanini Peres
ESALQ/USP

ESALQ/USP

UFSc/CCA/ARARAS

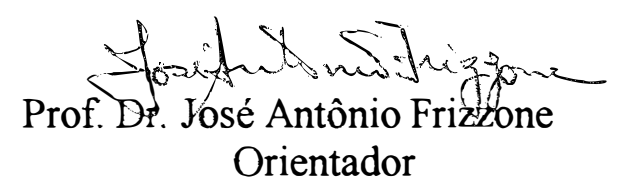




\section{AGRADECIMENTOS}

Ao Prof. Dr. José Antônio Frizzone, pela orientação.

Ao Coordenador do Curso de Pós-Graduação em Irrigação e Drenagem, Prof. Dr. Marcos Vinícius Folegatti, ao Dep. de Eng. Rural, a ESALQ/USP, pela oportunidade de realizar o Mestrado.

À CAPES, pela bolsa de estudo.

Ao INSTITUTO DE PESQUISAS TECNOLÓGICAS - IPT, pela infra estrutura fornecida para a realização das avaliações, em especial ao Dr. Geól. Antônio Melhem Saad, ao Téc. Márcio Lúcio Gonzaga, ao Téc. Agrícola Sebastião Fernandes, ao Téc. Agrícola José Aparecido e ao Téc. de Lab. Reginaldo Passos da Cruz.

À ASBRASIL S/A, pelo empréstimo do material utilizado na pesquisa de campo.

Ao Eng. Agrícola Antônio Alfredo T. Mendes, pelo apoio fornecido na pesquisa de campo.

Ao Sr. José Eduardo Croscato Lelis e funcionários da FAZENDA SANTA HELENA, pelo uso do sistema de irrigação pivô central.

A Hidroagro Com. e Sist. de Irrigação LTDA, pelo apoio fornecido na pesquisa de campo.

As bibliotecárias Eliana M. Sabino e Kátia M. Ferraz, pela revisão nas referências bibliográficas. 
Aos meus pais,

Tomaz e Maria Angela

À minha namorada,

Patricia

\section{OFEREÇO}

Aos meus irmãos,

Andréa, Marcos e Ricardo

Ao meu tio,

$$
\text { José Ângelo }
$$

À minha sobrinha

$$
\text { Marina }
$$

\section{DEDICO}




\section{SUMÁRIO}

\section{PÁGINA}

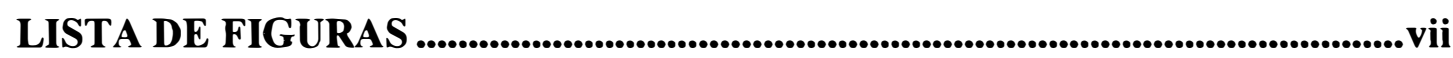

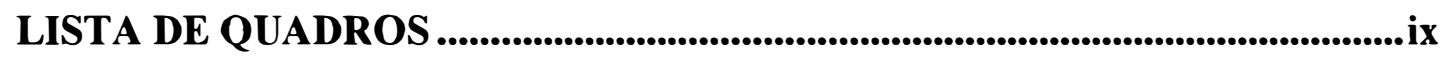

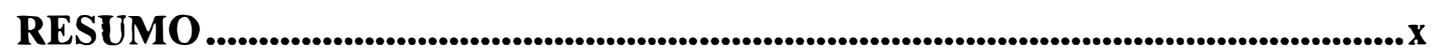

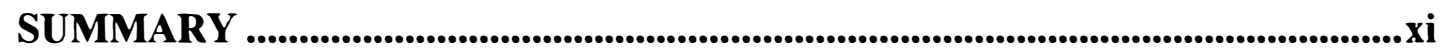

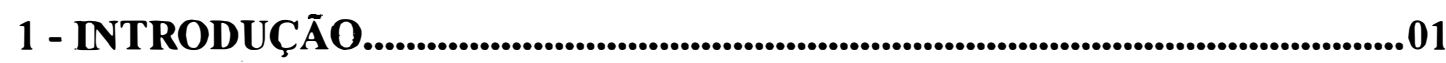

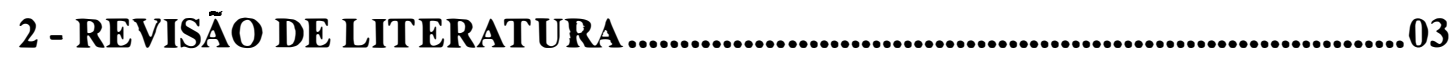

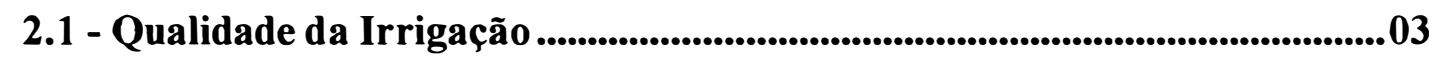

2.2 - Parâmetros de Desempenho....................................................................................05

2.2.1 - Uniformidade de Distribuição da Água.......................................................05

2.2.2 - Coeficiente de Uniformidade de Christiansen ..............................................08

2.2.3 - Fatores que Influenciam a Distribuição da

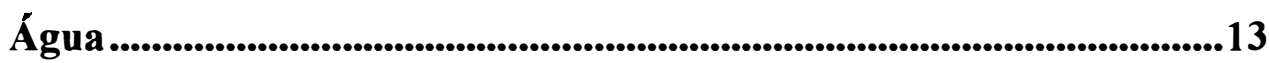

2.2.3.1 - Fatores Climáticos ............................................................................. 14

2.2.3.2 - Fatores Não Climáticos .................................................................16

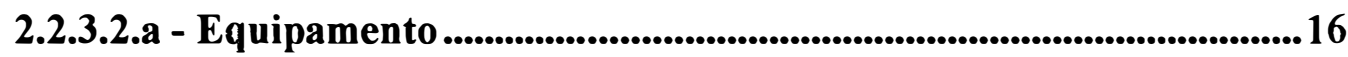

2.2.3.2.b - Metodologia de Avaliação.........................................................................18

3 - MATERIAL E MÉTODOS ..............................................................................20

3.1 - Caracterização da Área Experimental..........................................................20

3.2 - Descrição do Sistema de Irrigação Pivô Central ..................................................20

3.3 - Metodologia de Avaliação do Sistema...................................................................21

3.4 - Altura dos Emissores e Linhas Radiais de Coletores .........................................23

4 - RESULTADOS E DISCUSSÃO...............................................................................25

4.1 - Espaçamento entre Coletores .........................................................................39

4.1.1 - Emissor a $1,10 \mathrm{~m}$....................................................................................................40

4.1.2 - Emissor a $1,65 \mathrm{~m}$...............................................................................................................4 
4.1.3 - Emissor a 3,20 m......................................................................................................4

4.1.4 - Comparação entre as Três Alturas................................................................43

4.2 - Número de Linhas Radiais de Coletores.............................................................44

4.2.1 - Emissor a $1,10 \mathrm{~m}$......................................................................................................44

4.2.2 - Emissor a 1,65 m.................................................................................................4

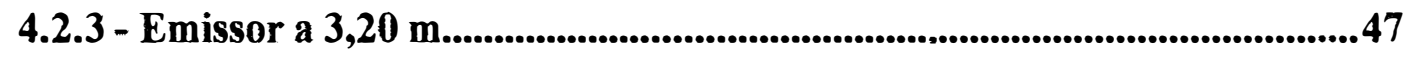

4.2.4 - Comparação entre as Três Alturas................................................................49

4.3 - Altura dos Emissores................................................................................................50

4.3.1 - Uma, Duas e Três Linhas Radiais..................................................................51

4.3.2 - Quatro Linhas Radiais.............................................................................53

4.3.3 - Comparação entre as quatro Linhas Radiais .............................................53

4.4 - Análise de Regressões..................................................................................................54

4.4.1 - Número de Linhas Radiais e Espaçamento entre os Coletores ..................................................................................................54

4.4.2 - Espaçamento entre os Coletores e Altura dos

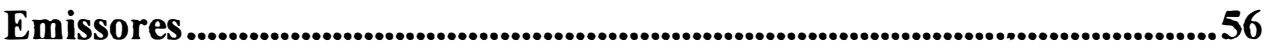

4.4.3 - Número de Linhas Radiais e Altura dos

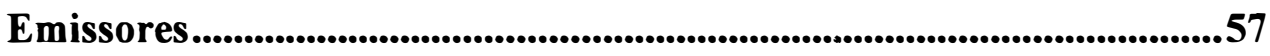

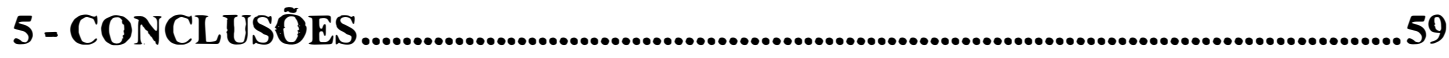

REFERÊNCIAS BIBLIOGRÁFICAS ..............................................................60 


\section{LISTA DE FIGURAS}

PÁGINA

FIGURA 1 - Esquema da área experimental

FIGURA 2 - Posições dos emissores, em relação à superfície de captação dos coletores .24

FIGURA 3 - Distribuição da água no teste 1A (4 linhas radiais de coletores), para os seguintes espaçamentos entre os coletores (a) 2,5 m, (b) 5,0 m, (c) 7,5 m, (d) 10,0 m e (e) 12,5 m

FIGURA 4 - Distribuição da água no teste 1B (4 linhas radiais de coletores), para os seguintes espaçamentos entre os coletores (a) 2,5 m, (b) 5,0 m, (c) 7,5 m, (d) 10,0 m e (e) 12,5 m .28

FIGURA 5 - Distribuição da água no teste $2 \mathrm{~A}$ (4 linhas radiais de coletores), para os seguintes espaçamentos entre os coletores (a) 2,5 m, (b) 5,0 m, (c) 7,5 m, (d) 10,0 m e (e) 12,5 m 29

FIGURA 6 - Distribuição da água no teste 2B (4 linhas radiais de coletores), para os seguintes espaçamentos entre os coletores (a) 2,5 m, (b) 5,0 m, (c) 7,5 m, (d) $10,0 \mathrm{~m} \mathrm{e} \mathrm{(e)} 12,5 \mathrm{~m}$.

FIGURA 7 - Distribuição da água no teste 3A (4 linhas radiais de coletores), para os seguintes espaçamentos entre os coletores (a) 2,5 m, (b) 5,0 m, (c) 7,5 m, (d) $10,0 \mathrm{~m}$ e (e) $12,5 \mathrm{~m}$. 31

FIGURA 8 - Distribuição da água no teste 3B (4 linhas radiais de coletores), para os seguintes espaçamentos entre os coletores (a) 2,5 m, (b) 5,0 m, (c) 7,5 m, (d) 10,0 m e (e) 12,5 m

FIGURA 9 - Distribuição da água no teste $1 \mathrm{~A}$ (espaçamento de 2,5 m entre coletores), para (a) 1 linha radial, (b) 2 linhas radiais, (c) 3 linhas radiais e (d) 4 linhas radiais 33 
FIGURA 10 - Distribuição da água no teste $1 \mathrm{~B}$ (espaçamento de $2,5 \mathrm{~m}$ entre coletores), para (a) 1 linha radial, (b) 2 linhas radiais, (c) 3 linhas radiais e (d) 4 linhas radiais

FIGURA 11 - Distribuição da água no teste $2 \mathrm{~A}$ (espaçamento de $2,5 \mathrm{~m}$ entre coletores), para (a) 1 linha radial, (b) 2 linhas radiais, (c) 3 linhas radiais e (d) 4 linhas radiais

FIGURA 12 - Distribuição da água no teste $2 \mathrm{~B}$ (espaçamento de $2,5 \mathrm{~m}$ entre coletores), para (a) 1 linha radial, (b) 2 linhas radiais, (c) 3 linhas radiais e (d) 4 linhas radiais

FIGURA 13 - Distribuição da água no teste 3A (espaçamento de $2,5 \mathrm{~m}$ entre coletores), para (a) 1 linha radial, (b) 2 linhas radiais, (c) 3 linhas radiais e (d) 4 linhas radiais

FIGURA 14 - Distribuição da água no teste 3B (espaçamento de $2,5 \mathrm{~m}$ entre coletores), para (a) 1 linha radial, (b) 2 linhas radiais, (c) 3 linhas radiais e (d) 4 linhas radiais

FIGURA 15 - Valores de CUC, para cinco espaçamentos diferentes entre os coletores, para 1, 2, 3 e 4 linhas radiais e três alturas dos emissores (a) $1,10 \mathrm{~m}$, (b) $1,65 \mathrm{~m} \quad \mathrm{e}$ (c) $3,20 \mathrm{~m}$ respectivamente

FIGURA 16 - Valores de CUC para 1, 2, 3 e 4 linhas radiais, cinco espaçamentos diferentes entre coletores e três alturas dos emissores (a) 1,10 m, (b) 1,65 m e (c) 3,20 m 48

FIGURA 17 - Valores de CUC para 1, 2, 3 e 4 linhas radiais e três alturas diferentes dos emissores, para os espaçamentos entre os coletores (a) 2,5 m, (b) 5,0 m, (c) 7,5 m, (d) 10,0 m e (e) 12,5 m 51

FIGURA 18 - Valores de CUC, em cinco espaçamentos diferentes entre os coletores e a três alturas diferentes dos emissores para 1 (a), 2 (b), 3 (c) e 4 (d) linhas radiais 


\section{LISTA DE QUADROS}

PÁGINA

Quadro 1 - Características do pivô central.........................................................20

Quadro 2 - Combinações possíveis com 4 linhas radiais .............................................23

Quadro 3 - Características do sistema de irrigação e velocidade média dos ventos durante as avaliações de desempenho ......................................25

Quadro 4 - Valores médios de CUC e resultados da análise estatística, em função do espaçamento entre os coletores, para 1, 2, 3 e 4 linhas radiais de coletores e três alturas de emissores em relação aos coletores

Quadro 5 - Variação dos valores médios de CUC, para os diferentes espaçamentos entre os coletores, em relação àqueles obtidos com espaçamento de 2,5 m entre os coletores, para 1, 2, 3 e 4 linhas radiais e três alturas dos emissores em relação aos coletores.

Quadro 6 - Valores médios de CUC e resultados da análise estatística, em função do número de linhas de coletores para cinco diferentes espaçamentos entre os coletores e três alturas do emissor em relação aos coletores

Quadro 7 - Variação dos valores médios de CUC, em \%, para 1, 2, 3 e 4 linhas radiais, em relação àqueles obtidos com 1 linha radial, em diferentes espaçamentos entre os coletores e três alturas dos emissores .46

Quadro 8 - Valores médios de CUC e resultado da análise estatística, em função da altura dos emissores para cinco diferentes espaçamentos e 1, 2, 3 e 4 linhas radiais. 


\title{
INFLUÊNCIA DO ESPAÇAMENTO ENTRE COLETORES, DO NÚMERO DE LINHAS RADIAIS E DA ALTURA DO EMISSOR NO COEFICIENTE DE UNIFORMIDADE DE CHRISTIANSEN PARA PIVÔ CENTRAL
}

\author{
Autor: ALEXANDRE BRYAN HEINEMANN \\ Orientador: PROF. DR. JOSÉ ANTÔNIO FRIZZONE
}

\section{RESUMO}

Devido ao fato do equipamento pivô central adaptar-se a diferentes condições edafoclimáticas, torna-se necessário a realização de avaliações de seu desempenho operacional. O objetivo deste trabalho foi analisar a influência do espaçamento entre coletores, do número de linhas radiais de coletores e da altura dos emissores, em relação à superfície de captação dos coletores, no coeficiente de uniformidade de Christiansen para a avaliação da uniformidade de distribuição da água por pivô central. Foram utilizadas cinco espaçamento entre coletores $(2,5 \mathrm{~m}, 5,0 \mathrm{~m}, 7,5 \mathrm{~m}, 10,0 \mathrm{~m}$ e $12,5 \mathrm{~m})$, quatro combinações de número de linhas radiais (1, 2, 3 e 4 linhas radiais) e três alturas de emissores $(1,10 \mathrm{~m}, 1,65 \mathrm{~m}$ e 3,20 m). De acordo com os resultados encontrados e nas condições em que o trabalho foi realizado, concluiu-se que:

- não houve efeito significativo dos espaçamentos entre coletores sobre o coeficiente de uniformidade de Christiansen.

- a utilização de duas linhas radiais constituiu a melhor condição para a determinação do coeficiente de uniformidade de Christiansen.

- a altura dos emissores apresentou efeito significativo sobre o coeficiente de uniformidade de Christiansen. 


\title{
THE INFLUNCE OF COLLECTOR SPACING, NUMBER OF RADIAL LNES AND SPRAY HEIGHT ON THE WATER DISTRIBUTION UNIFORMITY UNDER CENTER PIVOT IRRIGATION SYSTEM
}

\author{
Author: ALEXANDRE BRYAN HEINEMANN \\ Adviser: PROF. DR. JOSÉ ANTÔNIO FRIZZONE
}

\section{SUMMARY}

Due the center-pivot irrigation system adapte easily to different topographical and climate conditions, so it is necessary to evaluate the equipment performance under field conditions. The objective of this work is to analyze the influence of collector spacing, the number of radial lines and the spray height on the Christiansen uniformity coefficient of a center-pivot irrigation system. It was utilized five collector spaces (2,5 $\mathrm{m}, 5,0 \mathrm{~m}, 7,5 \mathrm{~m}, 10,0 \mathrm{~m}$ and 12,5 m), four number combination of radial line $(1,2,3$ and 4 ) and three spray heights $(1,10 \mathrm{~m}, 1,65 \mathrm{~m}$ and 3,20 $\mathrm{m})$. The following conclusions were found:

- the five spaces collector studied didn't show statistics difference for the Christiansen uniformity coefficient.

- two radial line was the better condition to determine the Christiansen uniformity coefficient

- all spray height analyzed showed statistics difference for the Christiansen uniformity coefficient. 


\section{1 - NTRODUÇÃO}

O sistema de irrigação por aspersão tipo pivô central vem aumentando gradativamente sua participação no contexto da irrigação no Brasil. Esse aumento gradativo no cenário da irrigação nacional se deve a algumas características particulares desse sistema, como:

- alto grau de automação;

- possibilidade de se variar a lâmina de água a ser aplicada;

- possibilidade de aplicar a água com alto grau de uniformidade;

- alto potencial para à prática de quimigação $\mathrm{e}$

- adaptação às diversas características topográficas.

Em razão do aumento do uso desse equipamento em diversas regiões, foram desenvolvidos acessórios para aumentar sua eficiência. Há possibilidades de se alterarem as placas dos emissores, assim como a altura dos mesmos em relação ao solo, através de dispositivos denominados tubos de descida. Essas práticas são muito úteis na realização da irrigação e quimigação em locais que possuem velocidade média do vento relativamente alta e baixa umidade relativa do ar nas épocas de maior demanda de uso do equipamento.

Devido ao equipamento pivô central se adaptar a diversas condições edafoclimáticas, torna-se necessárias a realização de avaliações do equipamento em condições de campo.

Um dos objetivos das avaliações em campo é a adequação da lâmina projetada à lâmina aplicada pelo equipamento com um bom grau de uniformidade de distribuição da água. No Brasil, essas avaliações de campo são regidas pelo projeto de norma da Associação Brasileira de Normas Técnicas (1985). 
A uniformidade de distribuição da água é um dos principais fatores a ser observado em sistemas de irrigação, devido a sua influência na produtividade agrícola. A uniformidade de distribuição da água é determinada quantitativamente através de coeficientes de uniformidade, sendo o mais conhecido o coeficiente de uniformidade de Christiansen (CUC).

Esse trabalho teve como objetivo estudar a influência do espaçamento entre coletores, do número de linhas radiais de coletores e da altura dos emissores, em relação à superficie de captação dos coletores, no coeficiente de uniformidade de Christiansen (CUC) para a avaliação da uniformidade de aplicação de água por pivô central. 


\section{2 - REVISÃO DE LITERATURA}

\section{1 - QUALIDAde DA IRRIGAÇÃo}

Devido à necessidade de conservação do recurso água, à competitividade pela água, ao custo da energia, ao custo de insumos e à estabilização dos preços dos produtos agrícolas, os sistemas de irrigação e os métodos de manejo da água devem proporcionar uma aplicação de água uniforme e eficiente.

Os equipamentos de irrigação têm ocupado lugar de destaque em função dos avanços tecnológicos que se verificam, tanto no âmbito das indústrias que os fabricam, como no campo do conhecimento agronômico sobre as relações água-solo-planta. Todavia essa evolução foi acompanhada por crescente complexidade, não só no nível da fabricação, das áreas de engenharia do produto, da engenharia de fabricação e da tecnologia básica (normalização, controle de qualidade, propriedade industrial e etc.), mas, principalmente, quanto à seleção e ao manejo otimizados desses equipamentos pelos usuários. Devido ao avanço tecnológico referido, os processos de tomada de decisão tornam-se mais dependentes de dados e informações sobre constantes construtivas, sobre especificações e parâmetros de desempenho, cuja obtenção constitui o objetivo fundamental dos ensaios dos equipamentos (Frizzone ${ }^{1}$ ).

A inserção da irrigação no processo de produção agrícola é uma decisão tomada com base na probabilidade de atingir-se um maior nível de eficácia na aplicação dessa técnica. A eficácia é definida como a relação entre o custo e o benefício e cuja maximização depende de fatores que vão desde as condições de mercado para produtos agrícolas, até as características de desempenho dos emissores de água (Frizzone ${ }^{\prime}$ ).

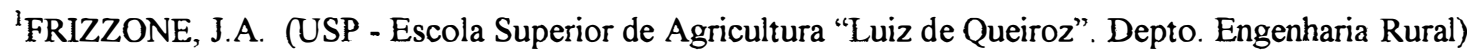
Notas de aula, 1995.
} 
Segundo o mesmo autor, há casos de sistemas que, por terem sido empiricamente projetados, apresentam baixa eficácia. Nesses casos, e também naqueles em que a eficácia do sistema nunca foi avaliada, a avaliação de desempenho constitui a única via para o levantamento dos dados necessários à tomada de decisão sobre melhorias a introduzir com vistas a elevação do nível de eficiência da irrigação. O autor define a avaliação de desempenho como a avaliação do sistema de irrigação, ou seja, o conjunto dos ensaios dos elementos que integram o sistema de irrigação sob julgamento. Já o ensaio é definido como uma avaliação dos elementos utilizados num sistema de irrigação, voltados a determinados atributos funcionais, de resistência ou durabilidade, como: máquinas, equipamentos, dispositivos, utensilios, etc.

O manejo racional da irrigação deve ser precedido por um programa de ensaio dos equipamentos em operação. Segundo Merrian \& Keller (1978), os ensaios têm aplicações locais práticas, mais imediatas, relacionadas à calibração dos equipamentos de forma a aumentar o grau de aproximação entre os valores de lâmina bruta, que se deseja aplicar, e aqueles realmente aplicados. Também têm como função a identificação de componentes que necessitam ser reparados e/ou substituídos (Bride, 1984).

De acordo com Hanson \& Lancaster (1986), uma avaliação de desempenho, a qual descreve as características de funcionamento do equipamento, tais como uniformidade e quantidade de água aplicada, entre outras, pode ajudar a identificar problemas no projeto e/ou no manejo de sistemas de irrigação por aspersão, os quais podem influenciar no custo de energia e no rendimento das culturas. Avaliações de desempenho de sistemas de irrigação pivô central são importantes para assegurar que os mesmos sejam instalados conforme especificados em projeto, devendo incluir ensaios das condições de operação do conjunto motobomba, rede de tubulação e uniformidade de distribuição da água dos emissores (Heermann, 1990). É sempre recomendável fazer avaliações periodicamente nos equipamentos de irrigação. Essa prática torna-se mais enfática quando se faz a quimigação através desses mesmos equipamentos (Ramos \& Mantovani, 1994).

Destacam se, na avaliação de desempenho de sistemas de irrigação, quatro objetivos (Frizzone', op. cit., p. 3): 
- determinar a eficiência do sistema na forma como vem sendo operado;

- determinar quão efetivamente o sistema pode ser operado e aperfeiçoado;

- obter informações que auxiliem os engenheiros no projeto de outros sistemas; e

- obter informações que permitam a comparação de vários métodos de irrigação, sistemas e formas de operação, como base para tomada de decisões gerencias.

\section{2 - PARÂMETROS DE DESEMPENHO}

A atual tendência dos especialistas na área é concentrar a quantificação de atributos dos sistemas de irrigação, em poucos parâmetros de desempenho, basicamente nomeados por três palavras chave: uniformidade, eficiência $\mathrm{e}$ grau de adequação/conformidade.

\subsection{1 - UNIFORMIDADE DE DISTRIBUIÇÃo DA ÁGUA}

O termo uniformidade é aplicado aos parâmetros de desempenho associados à variabilidade da lâmina de água ao longo da extensão da superficie do terreno irrigado (Frizzone' ${ }^{1}$ op. cit., p. 3). Todos os métodos de irrigação apresentam variabilidade na distribuição da lâmina de água.

A uniformidade tem impacto na eficiência dos sistemas de irrigação, o qual se caracteriza pela quantidade de água necessária ao desenvolvimento e ao rendimento de uma determinada cultura. Bernardo (1989), Daker (1984), Letey (1985), Hunsaker \& Bucks (1987) e Solomon (1984) afirmam que a uniformidade dos sistemas de irrigação tem efeito no rendimento das culturas.

O objetivo de obter-se maior uniformidade é devido ao fato de que a aplicação de água com baixa uniformidade pode elevar as perdas por escoamento superficial e por percolação (Hoffman \& Martin, 1993). Conforme salienta Bernardo (1989), para se obter uma boa uniformidade na distribuição da água sobre uma área irrigada, os emissores devem ser espaçados de modo a que ocorra uma sobreposição entre os perfis de distribuição de água dos emissores, ao longo da linha lateral e entre linhas laterais, ao 
longo da linha principal. A porcentagem de sobreposição recomendada dependerá do tipo de emissor e da intensidade do vento na área a ser irrigada.

O mínimo requerido para o desempenho favorável de um sistema de irrigação por aspersão é que seja atingida uma distribuição uniforme da lâmina de água aplicada e que a intensidade de aplicação não cause escoamento superficial durante a operação normal do sistema (Heermann \& Hein, 1968 e Scaloppi, 1984).

A determinação do coeficiente de uniformidade de distribuição da água permite observar a homogeneidade da distribuição da mesma sobre a área e verificar o funcionamento do pivô central, segundo Guerra ${ }^{2}$, citado por D'Assunp̧̧ão (1990).

Normalmente, o coeficiente de uniformidade é utilizado apenas como um indicador quantitativo da uniformidade de distribuição da água, sem um significado físico. Ben-Asher \& Ayars (1990), em um estudo teórico, prognosticaram o impacto da não uniformidade nas perdas de água por percolação. Segundo esses autores, com o decréscimo do coeficiente de uniformidade de Christiansen, maior é a quantidade de água percolada para uma dada aplicação de água.

A melhora da uniformidade de um sistema de irrigação é a decisão mais importante para o manejo adequado da água aplicada. De acordo com Duke et al. (1992), aumentar o coeficiente de uniformidade de Christiansen de 81,8 \% para 96,8\% equivale a aumentar a vazão em $27 \%$, quando se usa a estratégia de manejo com um grau de adequação de $75 \%$ ( $75 \%$ da área irrigada recebe no mínimo a lâmina média $)$. Heinemann \& Frizzone (1995) concluíram que o aumento do coeficiente de uniformidade de Christiansen, em um sistema pivô central, de 81,21 \% para um nível de $94,00 \%$, para os graus de adequação de 75,80 e $85 \%$, foi responsável por uma economia no volume de água aplicada de $11,86 \%, 14,24 \%$ e 16,68 \%, respectivamente.

A irrigação com alta uniformidade proporciona melhores resultados econômicos para qualquer combinação de custo da água e preço do produto ( $\mathrm{Paz}, 1995)$.

Por outro lado, um alto valor no coeficiente de uniformidade de Christiansen é fator essencial para o sucesso da quimigação, devido ao fato de a uniformidade na

\footnotetext{
${ }^{2}$ GUERRA, H.O.C. Irrigação por pivô central no serviço de produção de sementes básicas (Bebedouro II)
} Avaliação técnica. Petrolina: EMBRAPA-CPATSA, Documento n. 51, 1988. 100 p. 
distribuição do produto quimico ser, geralmente, proporcional à uniformidade na distribuição da água. Isso torna os equipamentos de irrigação por aspersão pivô central e linear móvel op̧̧ões das mais adequadas para a quimigação (Vieira, 1994).

Geralmente o coeficiente de uniformidade é utilizado para avaliar somente uma irrigação. Entretanto, de acordo com Pair (1968), torna-se mais interessante avaliar a uniformidade de várias irrigações, porque o coeficiente de uniformidade, de modo geral, aumenta quando se utilizam os valores das lâminas coletadas de várias irrigações.

Em geral, os coeficientes de uniformidade podem ser divididos em duas categorias: não-ponderados e ponderados (Marek et al., 1986). Em sistemas de irrigação por aspersão, nos quais cada emissor representa uma mesma área, os coeficientes de uniformidade são calculados sem a necessidade de ponderação. De forma geral, os coeficientes de uniformidade não ponderados e suas respectivas simbologias são:

CUC - coeficiente de uniformidade de Christiansen, proposto por Christiansen (1942);

CUE - coeficiente de uniformidade estatístico, proposto por Wilcox \& Swailes;

CUH - coeficiente de uniformidade havaiano, proposto por Hart;

UD - uniformidade de distribuição, proposto por Kruse e

UDH - uniformidade de distribuição havaiano, proposto por Hart.

Para os coeficientes de uniformidade ponderados, um valor numérico é associado à observação. É utilizado, geralmente em sistemas de irrigação por aspersão pivô central, nos quais os coletores são dispostos radialmente, a partir do ponto do pivô, com espaçamentos iguais entre si. Nesse caso, há necessidade de ponderar os valores observados, uma vez que cada coletor representa área maior à medida que se afasta do ponto central. Os coeficientes de uniformidade ponderados e suas respectivas simbologias incluem:

$\mathrm{CUC}_{\mathrm{HH}}$ - coeficiente de uniformidade de Christiansen modificado, proposto por Heermann \& Hein (1968);

UD - uniformidade de distribuição, proposto pelo Soil Conservation Service (SCS); CUE - coeficiente de uniformidade estatístico, proposto por Marek et al. (1986) e CUV - coeficiente de uniformidade de variação, proposto por Bremond \& Molle (1995). 
A norma S436, da American Society of Agricultural Engineers (1991) recomenda o uso do coeficiente de uniformidade de Christiansen modificado por Heermann \& Hein, para avaliação de sistema de irrigação por aspersão pivô central.

A uniformidade na distribuição da água é um parâmetro importante para avaliar um sistema de irrigação, visto que o propósito de tal sistema é aplicar água uniformemente, fornecendo condições para se obter um ótimo rendimento da cultura.

Para aumentar a uniformidade na distribuição da água por um sistema de irrigação, ou substituí-lo por outro sistema com maior capacidade de aplicar água uniformemente, devem-se levar em consideração as respostas biológicas das culturas e a relação custo/benefício que irá proporcionar. Os modelos biológicos e econômicos são complexos e devem ser avaliados em conjunto com a uniformidade de distribuição da água. Todavia esses modelos não podem ser expressos somente em função da uniformidade da irrigação (Heermann et al., 1990).

\subsection{2 - COEFICIENTE DE UNIFORMIDAdE DE CHRISTIANSEN}

O coeficiente de uniformidade de Christiansen (CUC), desenvolvido por Christiansen (1942), é o índice mais utilizado para a quantificação da uniformidade na distribuição da água em irrigação por aspersão convencional. Tal coeficiente é expresso pela seguinte equação:

$$
C U C=100\left(1-\frac{\sum_{i=1}^{n}\left|x_{i}-x_{m}\right|}{n x_{m}}\right)
$$

em que:

CUC - coeficiente de uniformidade de Christiansen, em \%;

n - número de coletores na área entre quatro emissores;

$\mathbf{X}_{\mathbf{i}}$ - lâmina de água coletada no i-ésimo coletor, em mm;

$X_{m}$ - valor médio das lâminas de água coletadas, em $\mathrm{mm}$. 
As indústrias de equipamento para irrigação por aspersão têm geralmente utilizado o CUC para comparação e avaliação dos sistemas de irrigação (Heermann \& Hein, 1968).

Marek et al. (1986), que compararam o CUC ao coeficiente de variação (CV), concluíram que o $\mathrm{CV}$ é mais adequado para comparações de sistemas de irrigação por aspersão pivô central.

Klar (1991) considera o CUC pouco sensível, devido ao mesmo utilizar, como medida de dispersão, o desvio médio absoluto (média aritmética do valor absoluto das diferenças entre cada lâmina de irrigação aplicada ao terreno e à lâmina média). Desvios negativos e positivos são considerados de igual efeito, o que não é verdadeiro para as plantas. Diferentes distribuições de água podem produzir valores de CUC semelhantes. Frizzone (1992) afirma que nenhum dos coeficientes de uniformidade, já apresentados como alternativa, mostrou vantagens significativas sobre o CUC.

Os valores de CUC, para pivôs centrais, eram calculados pela equação (1), não ocorrendo ponderações sobre a área que cada coletor representa (Rapp et al., 1979). Heermann \& Hein (1968) elaboraram um coeficiente de uniformidade similar, mas utilizando, como fator de ponderação, a distância do coletor i ao ponto do pivô. O coeficiente é expresso pela equação:

$$
\text { CUC }=100\left(1-\frac{\sum_{i=1}^{n}\left|V_{i}-V_{m}\right|}{n V_{m}}\right)
$$

em que:

$V_{\mathbf{i}}$ - volume coletado no i-ésimo coletor, representativo da i-ésima área $\left(A_{i}\right)$;

$V_{m}$ - volume médio coletado.

A equação (2) é semelhante à equação (1), mas expressa em unidades de volume os dados coletados. $O$ volume $V_{i}$ pode ser expresso por:

$$
V_{i}=A_{i} X_{i}
$$


e a área de abrangência de cada coletor será:

$$
A_{i}=\pi R_{2 i}^{2}-\pi R_{1 i}^{2}
$$

sendo:

$$
\begin{aligned}
& R_{1 i}=R_{i}-\frac{S}{2} \\
& R_{2 i}=R_{i}+\frac{S}{2}
\end{aligned}
$$

em que:

$\mathbf{R}_{\mathbf{i}}$ - distância do ponto do pivô ao i-ésimo coletor;

S - espaçamento entre coletores.

A equação (4) pode então ser reescrita da seguinte forma:

$$
A_{i}=2 \pi R_{i} S
$$

Substituindo a equação (6) na equação (3), tem-se:

$$
V_{i}=2 \pi R_{i} S X_{i}
$$

$\mathrm{O}$ volume médio coletado na i-ésima área $\left(\mathbf{V}_{\mathbf{m i}}\right)$ é igual ao produto desta pela lâmina média $\left(\mathbf{X}_{\mathbf{m}}\right)$, isto é:

$$
V_{m i}=A_{i} X_{m}
$$

A lâmina média de todas as observações é obtida pela relação entre o volume total coletado e a área total, ou seja: 


$$
x_{m}=\frac{\sum_{i=1}^{n} v_{i}}{\sum_{i=1}^{n} A_{i}}
$$

O volume médio $\left(\mathbf{V}_{\mathbf{m}}\right)$ aplicado pelo sistema é dado por:

$$
v_{m}=\frac{\sum_{i=1}^{n} A_{i} X_{i}}{n}
$$

resultando em:

$$
V_{m}=\frac{\sum_{i=1}^{n} 2 \pi S X_{i} R_{i}}{n}
$$

Substituindo-se as equações (11), (8) e (7) na equação (2), tem-se:

$$
C U C=100\left(1-\frac{\sum_{i=1}^{n}\left|2 \pi X_{i} R_{i} S-\frac{2 \pi R_{i} S \sum_{i=1}^{n} 2 \pi X_{i} R_{i} S}{\sum_{i=1}^{n} 2 \pi R_{i} S}\right|}{\sum_{i=1}^{n} 2 \pi X_{i} R_{i} S}\right)
$$

resultando em:

$$
C U C=100\left(1-\frac{\sum_{i=1}^{n} R_{i}\left|x_{i}-\frac{\sum_{i=1}^{n} x_{i} R_{i}}{\sum_{i=1}^{n} R_{i}}\right|}{\sum_{i=1}^{n} x_{i} R_{i}} \mid\right.
$$


em que:

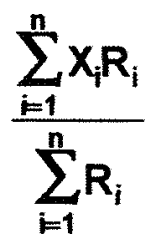

é a lâmina média ponderada de todas as observações.

É comum utilizar uma forma simplificada da equação (13), na qual as lâminas coletadas são ponderadas pelo respectivo número do coletor. Nesse caso, os coletores devem estar eqüidistantes e o número na escala natural, em ordem crescente, a partir do ponto do pivô. Efetua-se a simplificação da seguinte forma:

$$
\begin{aligned}
R_{1} & =1 S \\
R_{2} & =2 S \\
& \\
R_{i} & =i S
\end{aligned}
$$

e,

$$
\sum_{i=1}^{n} X_{i} R_{i}=\sum_{i=1}^{n} X_{i} S=S \sum_{i=1}^{n} X_{i} i
$$

Assim, substituindo-se as equações (14) e (15), na equação (13), tem-se:

$$
\operatorname{CUC}=100\left(1-\frac{\sum_{i=1}^{n} i\left|x_{i}-\frac{\sum_{i=1}^{n} x_{i} i}{\sum_{i \neq i}^{n} i}\right|}{\sum_{i=1}^{n} x_{i} i} \mid\right.
$$




\subsection{3 - FATORES QUE INFLUENCIAM A DISTRIBUIÇÃO DA ÁGUA}

O padrão de distribuição de um emissor depende de vários fatores como modelo do emissor, diâmetro do bocal, ângulo de saída do jato, pressão de operação e formato do bocal do emissor. Em condições de campo, depende também da temperatura do ar, da umidade relativa do ar e das condições do vento.

Para Heermann \& Hein (1968), a uniformidade na distribuição da água, em um sistema de irrigação por aspersão pivô central, não é função apenas da pressão de operação, mas também do aumento do tamanho e da vazão dos emissores, proporcionalmente ao aumento da área coberta pelos mesmos.

Segundo Pair (1968) vários fatores podem afetar a distribuição da água sobre o solo e a cultura. Eles podem ser agrupados em quatro classes:

a) emissor - diâmetro do bocal, ângulo de saída do jato, velocidade de rotação, pressão no bocal e quantidade e tipo de bocal;

b) sistema de distribuição - espaçamento entre emissores na linha lateral do sistema, espaçamento das linhas laterais ao longo da linha principal, altura do emissor em relação ao solo, estabilidade do emissor em funcionamento e variação da pressão no sistema;

c) climáticos - velocidade e direção do vento e

d) manejo - tempo de operação do sistema, velocidade de deslocamento da linha lateral em sistemas autopropulsores, alinhamento das linhas laterais e alinhamento do emissor com a vertical.

O modelo de distribuição de água de emissores sobrepostos depende das características estruturais e operacionais dos emissores, do espaçamento entre eles e das condições de vento que prevalecem durante o período de operação (Scaloppi, 1984).

De acordo com Thooyamani et al. (1987), o principal objetivo de um sistema de irrigação pivô central, de baixa pressão, é aplicar uma determinada lâmina de água com distribuição uniforme sobre a área irrigada, com a mínima quantidade de escoamento superficial. Os principais fatores que afetam tal desempenho são: 
- diâmetro da tubulação, diâmetro dos bocais, espaçamento, altura e pressão de operação dos emissores;

- padrão de distribuição do emissor;

- velocidade de rotação do equipamento no campo;

- vento;

- característica da velocidade de infiltração do solo e

- topografia.

Os três primeiros fatores são essencialmente função do equipamento, podendo ser caracterizados através de ensaios. Os outros fatores dependem das condições locais onde o equipamento operar.

Cuenca (1989) afirma que a uniformidade na distribuição da água depende das combinações dos seguintes fatores:

- pressão de operação do emissor;

- diâmetro do bocal do emissor;

- efeito do vento e

- espaçamento entre emissores.

Para Frizzone (1992), os fatores que afetam a distribuição da água pelos emissores são:

- variação de vazão dos emissores ao longo da linha lateral;

- variação do perfil de distribuição da água dos emissores na área irrigada, devido à própria variabilidade entre os emissores;

- pressão de operação do emissor;

- vento e

- altura do emissor em relação ao solo.

\subsubsection{1 - FATORES Climáticos}

\section{Evaporação, temperatura do ar, umidade relativa e condições do vento}

Ali Arshad \& Berefoot (1978), em teste com emissores, variando a pressão de operação, a placa do emissor e os bocais, concluíram que, para pressões de operação 
entre 134 e $278 \mathrm{kPa}$, as perdas por evaporação mantiveram-se as mesmas. Para pressões de operação acima de $278 \mathrm{kPa}$, as perdas por evaporação aumentaram. De acordo com os autores, pressões de operação altas, quando combinadas com o aumento da velocidade do vento, resultam na distorção do padrão molhado dos emissores.

Rapp et al. (1979), estudando a influência do vento no coeficiente de uniformidade de Christiansen modificado $\left(\mathrm{CUC}_{\mathrm{HH}}\right)$, observaram que o mesmo é influenciado pela direção e velocidade do vento, sendo o efeito da direção do vento mais pronunciado.

Para Scaloppi (1986) a uniformidade na distribuição da água é prejudicada pelo vento nos sistemas de irrigação cujos emissores operam estacionados, como na aspersão convencional e no rolamento lateral, ou então operam em faixas, como os emissores autopropelidos. Os sistemas dos tipos pivô central, dotados de emissores proximamente instalados, apresentam desempenho menos influenciavel pelo vento.

Segundo Silva (1989), trabalhos de modelagem e simulação computacional têm mostrado que, em ordem decrescente de importância, fatores como temperatura da água, tamanho das gotas, umidade relativa e altura de instalação do emissor exercem efeito marcante na evaporação da água na irrigação por aspersão. Também a uniformidade na distribuição da água é afetada diretamente pelo vento, pois o mesmo causa distorção na aplicação de água pelo emissor. Em geral, quanto maior a velocidade do vento, menor será a uniformidade do sistema.

Abo-Ghobar (1992) salienta que fatores climáticos como a velocidade do vento, a temperatura do ar e sua umidade relativa afetam a uniformidade na distribuição da água por pivô central, principalmente em climas secos e quentes. A quantidade de água perdida devido à evaporação e à deriva pelo vento depende das condições climáticas em que o equipamento está operando. O vento interfere na distribuição de água dos emissores, de acordo com a altura do emissor em relação ao solo. Esse mesmo autor trabalhou com três alturas diferentes de emissores: $2,5 \mathrm{~m}, 1,75 \mathrm{~m}$ e $1,25 \mathrm{~m}$, em três pivôs centrais diferentes, numa faixa de vento que variou de $2,95 \mathrm{~m} / \mathrm{s}$ a $3,4 \mathrm{~m} / \mathrm{s}$, tendo verificado uma perda por evaporação diretamente proporcional à altura do emissor. 


\subsubsection{2 - FATORES NÃo Climáticos}

\subsubsection{2.a - Equipamento}

\section{Pressão de operação do emissor}

Os sistemas de irrigação por aspersão pivô central podem ser operados com pressões reduzidas, entre 134 a $278 \mathrm{kPa}$, resultando em uma uniformidade satisfatória e menores perdas por evaporação, desde que sejam observadas as recomendações para espaçamento entre emissores (Ali Arshad \& Berefoot, 1978).

Coelho (1990) trabalhou com emissores de impacto, modelo MD - 20A, e concluiu que a pressão de operação dos emissores interfere na distribuição da água. Com espaçamentos reduzidos entre emissores $(6 \times 12 \mathrm{~m} \mathrm{e} 12 \times 12 \mathrm{~m})$, as pressões maiores apresentaram melhores CUCs; em espaçamento maiores ( $12 \times 18 \mathrm{~m} \mathrm{e} 18 \times 18$ m), as pressões 20, 30 e 40 m.c.a. não diferiram significativamente quanto aos valores de CUC apresentados.

\section{Altura do emissor}

Algumas técnicas podem ser aplicadas em sistemas de irrigação por aspersão pivô central para reduzir as perdas por evaporação e escoamento, resultando num acréscimo da eficiência do sistema. Uma das técnicas utilizadas para tanto consiste na colocação de tubos de descida, de modo a diminuir a altura do emissor em relação à cultura.

Segundo Silva (1989), um aumento da uniformidade de distribuição da água em sistemas de irrigação pivô central, através de tubos de descida, depende da combinação entre o comprimento do tubo e a placa difusora. Se tal combinação não for adequada, haverá problemas de recobrimento e colisão de gotas.

Segundo James \& Blair (1984), emissores fixo de baixa pressão, montados sobre tubos de descida, a poucos centímetros da cultura, podem afetar o desempenho dos 
pivôs centrais. Os autores, através de um programa de simulação de uniformidade na distribuição da água, observaram que os pivôs centrais com tubo de descida apresentaram valores menores de coeficientes de uniformidade que aqueles sem os tubos.

Longo (1991) avaliou um pivô central de baixa pressão, com o emissor em quatro alturas diferentes (sem tubo de descida e equipados com tubos de descida a 1,2 $\mathrm{m}, 2,0 \mathrm{~m}$ e $2,6 \mathrm{~m}$ ) em condições de velocidade média do vento de $1,6 \mathrm{~m} / \mathrm{s}$ e umidade relativa do ar variando entre $55 \%$ a $68 \%$. O autor utilizou a metodologia clássica, com coletores espaçados a cada $5 \mathrm{~m}$ e concluiu que a variação da altura do emissor não afetou a uniformidade de distribuição da água. Por outro lado, Furukawa (1991), estudando o desempenho de cinco sistemas de irrigação por aspersão pivô central, em Rio Verde - GO, concluiu que os equipamentos que utilizaram tubos de descida apresentaram menores valores de CUC.

Teixeira (1992), avaliando o desempenho de um pivô central de baixa pressão, de acordo com o projeto de norma $n^{\circ} 12: 02.08-005$ ABNT (1985), observou que à medida que aumenta o comprimento do tubo de descida, ocorre uma redução do comprimento do jato, a sobreposição é prejudicada e ocorre um decréscimo na uniformidade.

Denículi et al. (1993) simularam valores de CUC, operando com um emissor fixo, modelo AF-1, em cinco alturas distintas ( $1,0 \mathrm{~m}, 1,5 \mathrm{~m}, 2,0 \mathrm{~m}, 2,5 \mathrm{~m} \mathrm{e} \mathrm{3,0} \mathrm{m)} \mathrm{em}$ relação ao solo e cinco inclinações em relação à vertical $(0,7,5 \%, 15 \%, 22,5 \%$ e 30 \%). Os autores observaram que, de modo geral, o aumento da altura de instalação do emissor resultou em crescimento nos valores de CUC. Esse trabalho considerou vento nulo.

De acordo com Miranda et al. (1994), para minimizar as perdas de água por evaporação e por arrastamento pelo vento (deriva), e diminuir a deformação do perfil de precipitação, utilizam-se tubos de descida, de comprimento variável, que permitem a aplicação da água mais próxima da cultura e do solo. Os respectivos autores simularam valores de CUC para um sistema linear, operando com emissor fixo, modelo AF-1, e com cinco alturas diferentes $(1,0 \mathrm{~m}, 1,5 \mathrm{~m}, 2,0 \mathrm{~m}, 2,5 \mathrm{~m}$ e 3,0 m) do emissor em relação 
ao plano formado pela superficie de captação dos coletores. Observaram que, em condições de vento nulo, a diminuição da altura do emissor causou uma redução dos valores de CUC.

\section{Velocidade e Alinhamento da Linha Lateral do Equipamento}

O fato de os sistemas de irrigação pivô central e linear móvel não possuírem um movimento uniforme de suas torres, devido à variações na velocidade, proporciona uma diminuição na uniformidade de distribuição da água. Hanson \& Wallender (1986) mediram e Heermann \& $\operatorname{Stahl}^{\Im}$ (1986), citados por Heermann et al. (1990), simularam o efeito do movimento descontínuo dos equipamentos pivô central e linear móvel na uniformidade circular. Esse decréscimo no coeficiente de uniformidade torna-se mais enfático quando os sistemas de irrigação são de baixa pressão e utilizados para fazer quimigação.

\subsubsection{2.b - Metodologia de Avaliação}

\section{Número de coletores e de linhas radiais de coletores}

De acordo com Davis (1966), a quantidade de coletores a utilizar e o espaçamento entre eles dependem da relação entre a quantidade de amostras necessárias para se obter um valor preciso e a facilidade e economia de se utilizarem poucas amostras nos testes. Segundo o mesmo autor, para uma distribuição uniforme, poucas amostras são necessárias para se obter um valor preciso. O problema para se determinar o número de coletores ocorre em distribuições não uniformes. $\mathrm{O}$ autor estudou quatro modelos de distribuição de coletores, com emissor de impacto e concluiu que a lâmina média aplicada foi praticamente a mesma para os quatros modelos, e que o tipo de modelo de distribuição de coletores e o grau de desuniformidade não influenciaram na consistência dos valores da lâmina média, para as várias densidades de amostragem.

${ }^{3}$ HEERMANN, D.F.; STAHL, K.M. Center pivot uniformity for chemigation. St. Joseph: ASAE, 1986. (ASAE Paper, 86-2584) 
D’Assunpção (1990), utilizando a metodologia de avaliação proposta por Merriam \& Keller (1978), testou três espaçamento entre coletores $(6,0 \mathrm{~m}, 12,0 \mathrm{~m}$ e 18,0 $\mathrm{m})$. Concluiu que, para espaçamentos maiores que $12,0 \mathrm{~m}$, ocorre um desagrupamento de dados, resultando em coeficientes superiores ou inferiores aos esperados. O equipamento testado possuía tubos de decida, com uma altura livre média de $0,80 \mathrm{~m}$ em relação ao solo e $0,30 \mathrm{~m}$ em relação aos coletores. A maioria dos testes apresentou valores de CUC abaixo de 70\%.

Bremond \& Molle (1995) através de um modelo de simulação de uniformidade de distribuição de água, analisaram a influência de cinco espaçamentos entre coletores (0,5 m, 1,5 m, 3,0 m, 5,0 m, 7,5 m e 10,0 m). Observaram que, com o aumento do espaçamento entre coletores (diminuição do número de coletores), ocorreu perda na precisão do cálculo dos coeficientes de uniformidade. Segundo os autores, tal perda é devido à ocorrência de valores extremos no final do pivô central. Para apenas uma linha radial, com espaçamento entre coletores maior que $5,0 \mathrm{~m}$, pode-se ter uma variação no valores de CUC de aproximadamente $1,25 \%$. Os mesmos autores concluíram que emissores que possuem um raio molhado menor que 10,0 $\mathrm{m}$ deveriam utilizar, na avaliação de desempenho, duas linhas de coletores radiais, com espaçamento menor ou igual a $5,0 \mathrm{~m}$.

A ASAE (1991) recomenda, para a avaliação de desempenho de equipamentos de irrigação por aspersão pivô central, a utilização de, no mínimo, duas linhas radias de coletores, não devendo a distância entre as linhas radiais, no final, ser maior que $20 \mathrm{~m}$. Quanto ao espaçamento entre coletores, nas linhas radiais, deverá ser $30 \%$ da média dos diâmetros molhados dos emissores.

De acordo com o projeto de norma $\mathrm{n}^{\circ}$ 12:02.08-005 ABNT (1985), deverão ser instaladas duas linhas radiais de coletores, com ângulo de $3^{\circ}$ aproximadamente entre elas, independente do comprimento das mesmas. Quanto ao espaçamento entre coletores, deverá ser, no máximo, 9,0 m, preferencialmente entre 4,0 e $6,0 \mathrm{~m}$, e corresponder, quando possível, a um submúltiplo do número de vãos do equipamento. 


\section{3 - MATERIAL E MÉTODOS}

\section{1 - CARACTERIZAÇão da Área EXPERIMENTAL}

A área do experimento está localizada a $20^{\circ} 27^{\prime} 30^{\prime \prime}$ de latitude sul e a $48^{\circ} 19^{\prime} 30^{\prime \prime}$ de longitude oeste, com altitude de 495 metros acima do nível do mar, situada na fazenda Santa Helena, no município de Guaíra, Estado de São Paulo.

$\mathrm{O}$ experimento foi conduzido em uma área de 2,4 ha, representando $2,75 \%$ da área total do pivô central.

O clima, segundo a classificação de Köeppen, é do tipo Cwa, subtropical com inverno seco, e temperatura média do mês mais frio inferior a $18^{\circ} \mathrm{C}$ e do mês mais quente, superior a $22^{\circ} \mathrm{C}$.

\section{2 - Descrição do Sistema de IrRigaÇão Pivô Central}

O equipamento utilizado no experimento foi um pivô central de baixa pressão, marca ASBRASI, modelo PA3-VSN. Algumas características do equipamento, são mostradas no Quadro 1.

Quadro 1 - Características do pivô central

\begin{tabular}{lc}
\hline \multicolumn{1}{c}{ Item } & Características \\
\hline Tipo de emissor & Difusor \\
Tipo de defletor & Plano com ranhura \\
Tipo de ranhura & Grossa com 36 estrias \\
Número de torres & 10 \\
Espaçamento médio entre emissores, em m & 2,13 \\
Velocidade de rotação a 100\%, em m/h & 275,50 \\
Comprimento lateral, em m & 526,40 \\
Comprimento do balanço, em m & 24,00 \\
\hline
\end{tabular}




\section{3 - Metodologia de Avaliação do Sistema}

Para as seis avaliações do sistema, foi utilizado como base o projeto de norma $\mathrm{n}^{\circ}$ 12:02.08-005 da ABNT (1985) para caracterização de desempenho. Determinaram-se: a velocidade do vento, de 5 em 5 minutos, com um anemômetro; a umidade relativa do ar, através de um psicrômetro de corda, realizando-se duas medidas, no inicio e final das avaliações; a água evaporada nos coletores, durante o período de cada avaliação, com quatro coletores com volume de água conhecido $(110 \mathrm{ml})$, mantidos próximos à área experimental e através da diferença do volume de água no início e final do teste, estimou-se a evaporação.

Para cada avaliação, a pressão de operação do sistema foi determinada através de um manômetro, tipo Bourdon com glicerina, na base do conjunto motobomba, na base do pivô e no último emissor de cada vão.

Os diâmetros molhados foram medidos com o auxilio de uma fita métrica, usada no centro do primeiro, quinto e décimo vãos do equipamento.

As avaliações foram realizadas com o equipamento a uma velocidade de 83,70 $\mathrm{m} / \mathrm{h}$, com o relé percentual a $30 \%$.

Foram locadas quatro linhas radiais de coletores, denominadas linhas $\mathrm{A}, \mathrm{B}, \mathrm{C}$ e D, conforme mostra a Figura 1. O alinhamento das mesmas foi feito de forma a se obter um ângulo de $3^{\circ}$ entre elas.

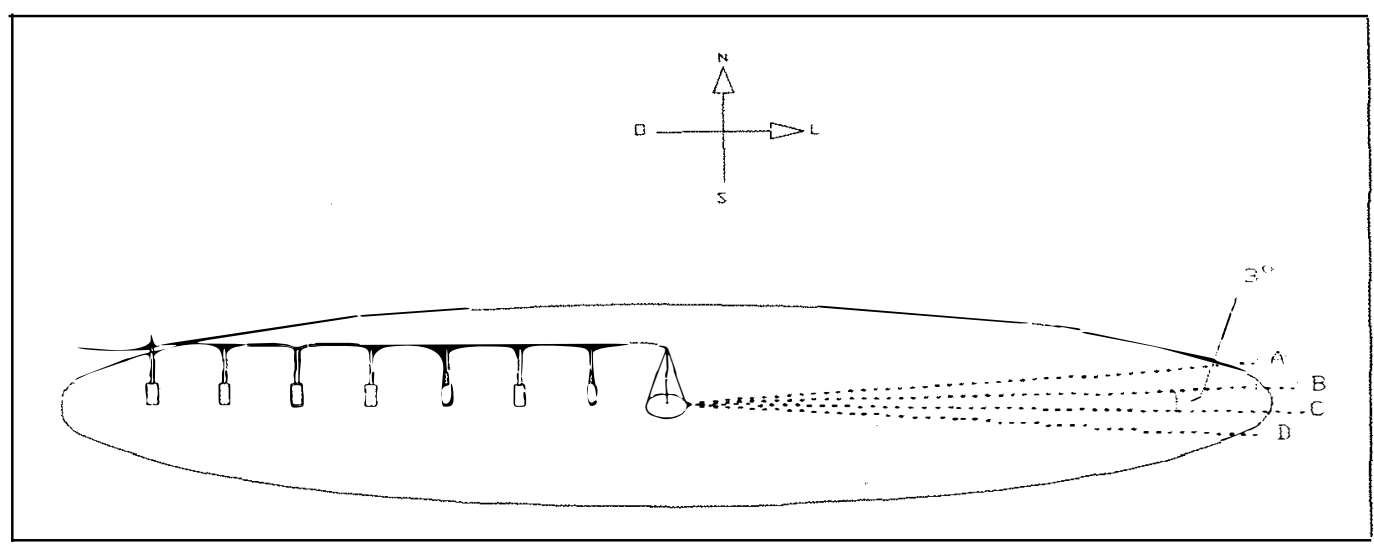

Figura 1 - Esquema da área experimental 
Em cada linha foram instalados 213 coletores, utilizando-se, nas quatros linhas, 852 coletores.

A diferença de nível entre a extremidade final de cada linha e a base do pivô central também foi determinada: $0,46 \%$ para a linha $A, 0,34 \%$ para a linha $B, 0,22 \%$ para a linha $C$ e $0,09 \%$ para a linha $D$.

Os coletores utilizados nas linhas radiais, com capacidade máxima de $350 \mathrm{ml}$, apresentavam uma área de captação de $50,26 \mathrm{~cm}^{2}$. Os mesmos foram instalados sobre suportes, ficando a uma altura média de $60 \mathrm{~cm}$ do solo, evitando a influência de respingos provenientes do solo. Em cada radial, os coletores foram numerados em ordem crescente, a partir da base do pivô.

A distância entre os coletores foi estabelecida de forma a permitir o cálculo dos valores de CUC nos espaçamentos 2,5 m, 5,0 m, 7,5 m, 10,0 m e 12,5 m. Os coletores foram dispostos no espaçamento de $2,5 \mathrm{~m}$ entre eles. A distância entre o primeiro coletor e a base do pivô foi de 2,5 m, estando o último coletor a 532,5 m mesma.

Os valores de CUC foram calculados através da equação (12). Para o cálculo da lâmina média utilizou-se a equação (9) e, para o cálculo do desvio padrão, a seguinte equação:

$$
s=\sqrt{\frac{\left.\sum_{i=1}^{n} R_{i}\left(\mid X_{i}-X_{m}\right)\right)^{2}}{\sum_{i=1}^{n} R_{i}}}
$$

em que:

s - desvio padrão, em mm;

$\mathbf{X}_{\mathbf{i}}$ - lâmina de água coletada no i-ésimo coletor, em mm;

$\mathbf{X}_{\mathbf{m}}$ - valor médio das lâminas de água coletadas, em mm;

$\mathbf{R}_{\mathbf{i}}$ - distância da base do pivô ao i-ésimo coletor, em $\mathrm{m}$.

De acordo com a ABNT (1985), os coletores à frente do raio final do equipamento, com volumes inferiores a $70 \%$ da média aritmética do total das medições, 
foram eliminados. Foram considerados para cálculo dos valores de CUC, da lâmina média, da área irrigada e do desvio padrão somente os coletores que, no início das linhas radiais, receberam volume de água.

\section{4 - AltURA dOS EMISSORES E LINHAS RADIAIS DE COLETORES}

No experimento foram realizadas seis avaliações de desempenho, sendo duas para cada altura dos emissores. Na altura 1, utilizou-se tubo de descida e prolongador. $\mathrm{O}$ equipamento possuía uma altura média livre de $1,10 \mathrm{~m}$, em relação à superficie dos coletores, conforme se ilustra na Figura 2 (a). Na altura 2, o pivô central possuía somente tubo de descida, com uma altura média livre de 1,65 $\mathrm{m}$ (Figura $2 \mathrm{~b}$ ) em relação à superficie dos coletores. $\mathrm{Na}$ altura 3 , utilizaram-se difusores sobre a linha lateral, cuja altura média em relação à superficie de coletores foi de 3,20 m (Figura $2 \mathrm{c}$ ).

As avaliações na altura 1 foram denominadas $1 \mathrm{~A}$ e $1 \mathrm{~B}$, na altura 2, 2A e $2 \mathrm{~B}$ e, na altura 3, 3A e 3B.

Em cada avaliação de desempenho, o equipamento passou sobre 4 linhas radiais de coletores (linhas A, B, C e D), conforme ilustra a Figura 1.

Para uma avaliação de desempenho, foram determinados 75 CUCs, através da combinação de linhas radiais e cinco espaçamentos diferentes entre os coletores. Para um determinado espaçamento entre coletores, obtiveram-se 15 CUCs, conforme mostra o Quadro 2.

Quadro 2 - Combinações possiveis com 4 linhas radiais.

\begin{tabular}{ccl}
\hline $\mathrm{N}^{\circ}$ de linhas radiais & $\mathrm{N}^{\circ}$ de CUC & Combinações de linhas radiais \\
\hline 1 & 4 & $(\mathrm{~A}),(\mathrm{B}),(\mathrm{C}) \mathrm{e}(\mathrm{D})$ \\
2 & 6 & $(\mathrm{~A}$ e B), $(\mathrm{A}$ e C), (A e D), (B e C), (B e D) e (C e D) \\
3 & 4 & $(\mathrm{~A}, \mathrm{~B}$ e C), (A, B e D), (B, C e D) e (A, C e D) \\
4 & 1 & $(\mathrm{~A}, \mathrm{~B}, \mathrm{C}$ e D) \\
\hline
\end{tabular}

$\mathrm{Na}$ altura de 1,10 m dos emissores, com duas avaliações (1 A e 1B), obtiveram-se 150 valores de CUC, sendo que, para o espaçamento de $2,5 \mathrm{~m}$ entre coletores, obtiveram-se 30 valores de CUC, sendo 8 para as linhas (A), (B), (C) e (D), 12 para as linhas (A e B), (B e C), (C e D), (A e C), (A e D) e (B e D), 8 para as linhas (A, B e C), 
(A, B e D), (B, C e D) e (A, C e D) e 2 para as linhas (A, B, C e D). Para os demais espaçamentos entre coletores e alturas dos emissores, usou-se o mesmo procedimento. Para as três alturas dos emissores em relação à superficie de captação dos coletores, determinaram-se 450 valores de CUC.

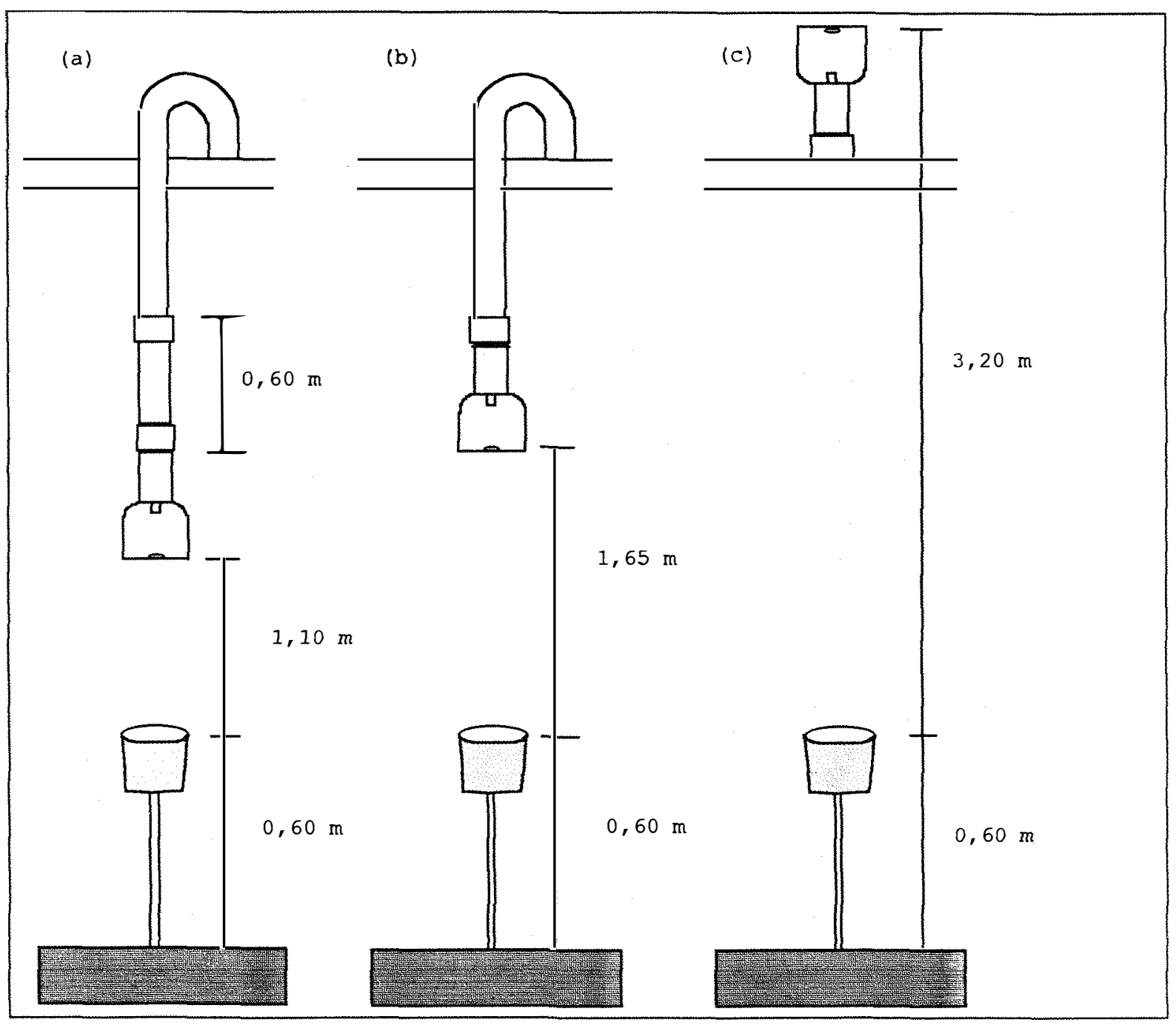

Figura 2 - Posições dos emissores, em relação à superfície de captação dos coletores. 


\section{4 - RESULTADOS E DISCUSSÃO}

O Quadro 3 apresenta os valores de velocidade média do vento, a umidade relativa do ar, a pressão do sistema em operação, a altura do emissor em relação à superfície dos coletores e o diâmetro molhado, para as avaliações de desempenho dos testes 1A, 1B, 2A, 2B, 3A e 3B.

Quadro 3 - Características do sistema de irrigação e velocidade média dos ventos durante as avaliações de desempenho.

\begin{tabular}{lcccccc}
\hline \multicolumn{1}{c}{ Parâmetros } & \multicolumn{7}{c}{ Testes } \\
\cline { 2 - 7 } & $1 \mathrm{~A}$ & $1 \mathrm{~B}$ & $2 \mathrm{~A}$ & $2 \mathrm{~B}$ & $3 \mathrm{~A}$ & $3 \mathrm{~B}$ \\
\hline Veloc. média do vento, em m/s & 3,20 & 1,50 & 2,10 & 2,40 & 2,20 & 1,71 \\
Pressão de "shut-off", em mca & 160,00 & 160,00 & 160,00 & 160,00 & 160,00 & 160,00 \\
Pressão na moto bomba, em mca & 107,00 & 107,00 & 109,00 & 109,00 & 105,00 & 105,00 \\
Pressão na base do pivô, em mca & 57,00 & 58,00 & 60,50 & 60,00 & 57,00 & 57,00 \\
Pressão no balanço, em mca & $12,20^{*}$ & $11,70^{*}$ & $13,92^{*}$ & $13,48^{*}$ & $16,30^{*}$ & $15,30^{*}$ \\
Altura do emissor, em m & 1,10 & 1,10 & 1,65 & 1,65 & 3,20 & 3,20 \\
Diâmetro molhado 1 $1^{\circ}$ vão, em m & 3,00 & 5,90 & 7,00 & 7,30 & 9,00 & 8,80 \\
Diâmetro molhado 5 $5^{\circ}$ vão, em m & 10,60 & 10,30 & 12,30 & 9,70 & 14,00 & 15,30 \\
Diâmetro molhado 10 $0^{\circ}$ vão, em m & 12,10 & 12,00 & 12,70 & 12,30 & 18,00 & 17,00 \\
Diâmetro molhado médio, em m & 8,60 & 9,40 & 10,70 & 9,80 & 13,70 & 13,70 \\
\hline
\end{tabular}

* Pressão após regulador de pressão do equipamento.

$1 \mathrm{mca} \cong 9,81 \mathrm{kPa}$

De acordo com os dados do Quadro 3, observa-se que o diâmetro molhado é influenciado pelo diâmetro do bocal dos emissores, pelas condições climáticas locais e pela altura dos emissores.

O diâmetro molhado no $1^{\circ}$ vão, para um mesmo teste, é menor que nos demais vãos, sendo que os emissores, no $1^{\circ}$ vão, possuem um diâmetro de bocal menor que nos demais vãos. Para todos os testes, observa-se um aumento do diâmetro molhado em função do aumento do diâmetro do bocal. 
Para as três alturas distintas de emissores, num mesmo vão, obtêm-se valores de diâmetro molhado diferentes. Para todos os testes, observa-se um aumento do diâmetro molhado em função do aumento da altura do emissor.

Para dois testes com os emissores na mesma altura e condições climáticas diferentes, obtêm-se diâmetros molhados diferentes num mesmo vão. Isso ocorreu devido a variações das condições climáticas locais, entre um teste e outro.

Tais resultados estão de acordo com as afirmações de Pair (1968), Thooyamani et al. (1987), Cuenca (1989) e Frizzone (1992).

As Figuras 3, 4, 5, 6, 7 e 8 representam graficamente a distribuição da água do pivô central e a lâmina média aplicada, utilizando-se quatro linhas de coletores, para os espaçamentos (a) 2,5 m, (b) 5,0 m, (c) 7,5 m, (d) 10,0 m e (e) $12,5 \mathrm{~m}$ dos testes 1A, 1B (altura média dos emissores de 1,10 m), 2A, 2B (altura média dos emissores de 1,65 m) e 3A e 3B (altura média dos emissores de 3,20 m).

As Figura 9, 10, 11, 12, 13 e 14 representam graficamente a distribuição da água do pivô central e a lâmina média aplicada, utilizando-se, como espaçamento entre os coletores, $2,5 \mathrm{~m}$, para os seguintes números de linhas de coletores: (a) 1, (b) 2 , (c) $3 \mathrm{e}$ (d) 4 para os testes $1 \mathrm{~A}, 1 \mathrm{~B}, 2 \mathrm{~A}, 2 \mathrm{~B}, 3 \mathrm{~A}$ e $3 \mathrm{~B}$. 

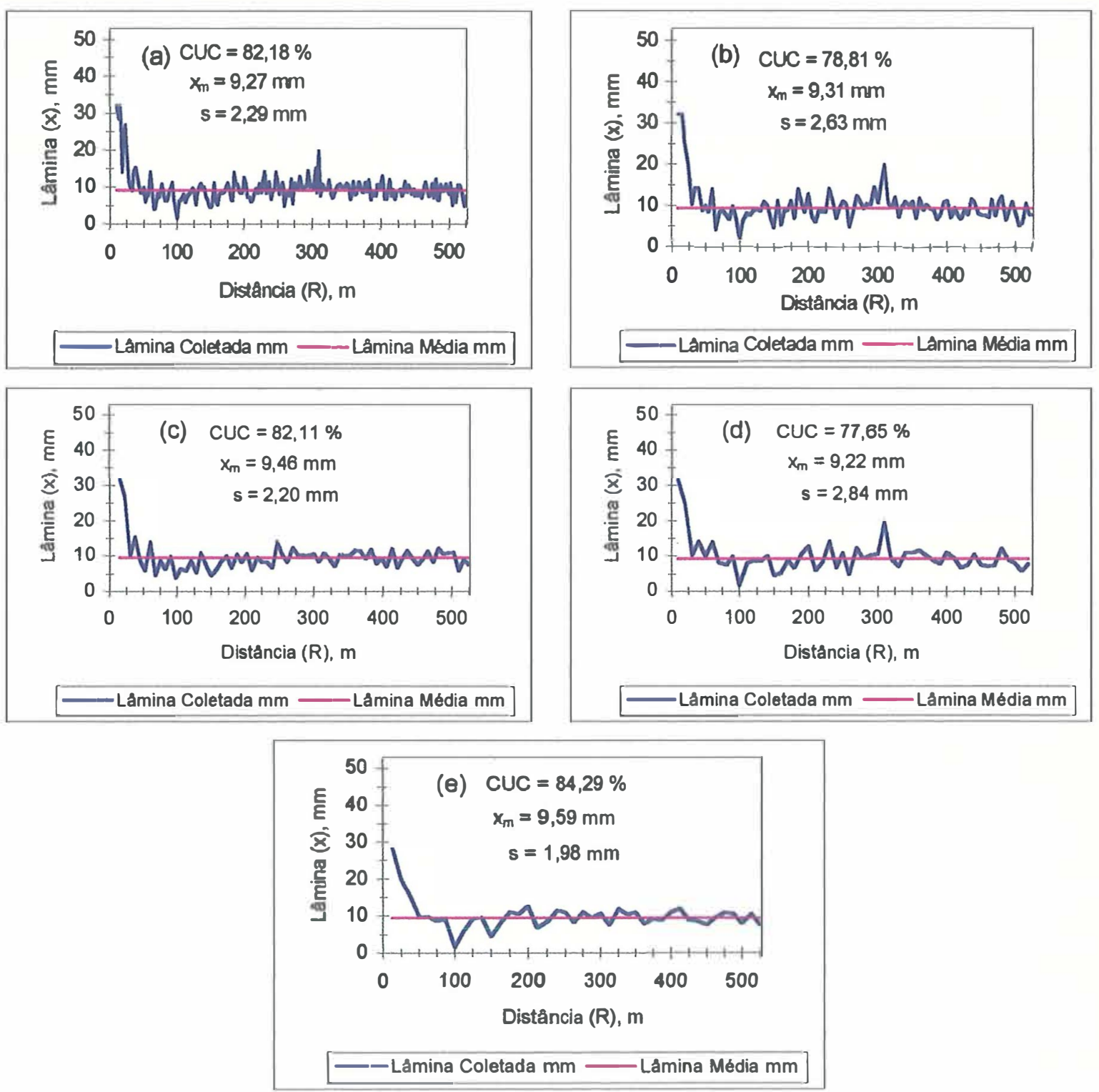

Figura 3 - Distribuição da água no teste 1A (4 linhas radiais de coletores), para os seguintes espaçamentos entre os coletores (a) 2,5 m, (b) 5,0 m, (c) 7,5 m, (d) $10,0 \mathrm{~m} \mathrm{e}(\mathrm{e}) 12,5 \mathrm{~m}$. 

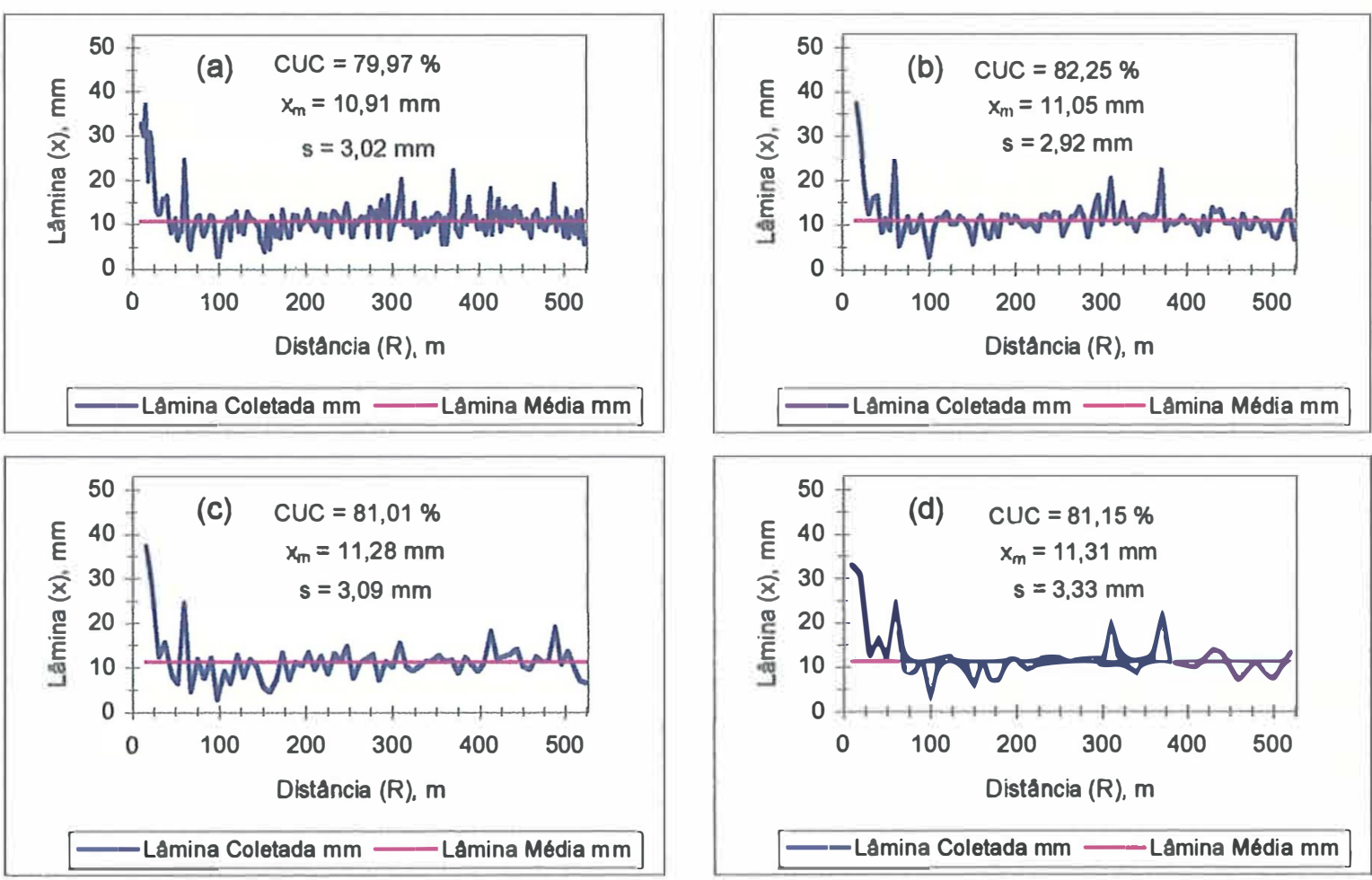

—— Lâmina Coletada mm — Lâmina Média mm

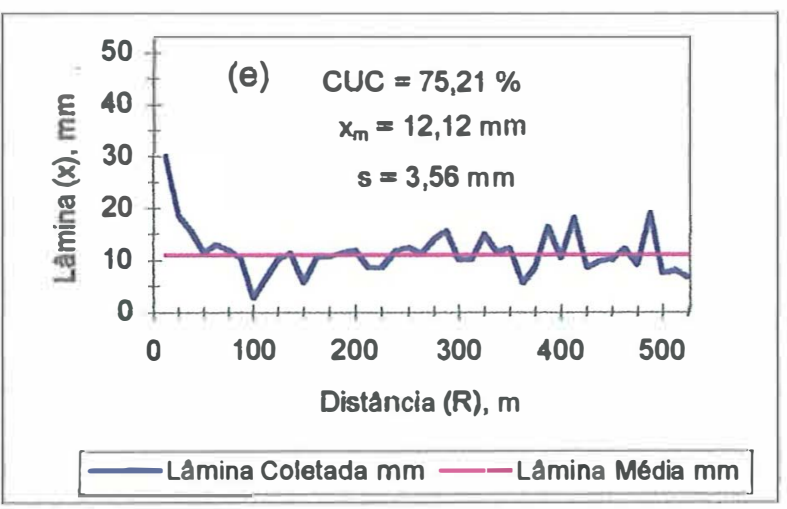

Figura 4 - Distribuição da água no teste 1B (4 linhas radiais de coletores), para os seguintes espaçamentos entre os coletores (a) 2,5 m, (b) 5,0 m, (c) 7,5 m, (d) $10,0 \mathrm{~m} \mathrm{e}(\mathrm{e}) 12,5 \mathrm{~m}$. 

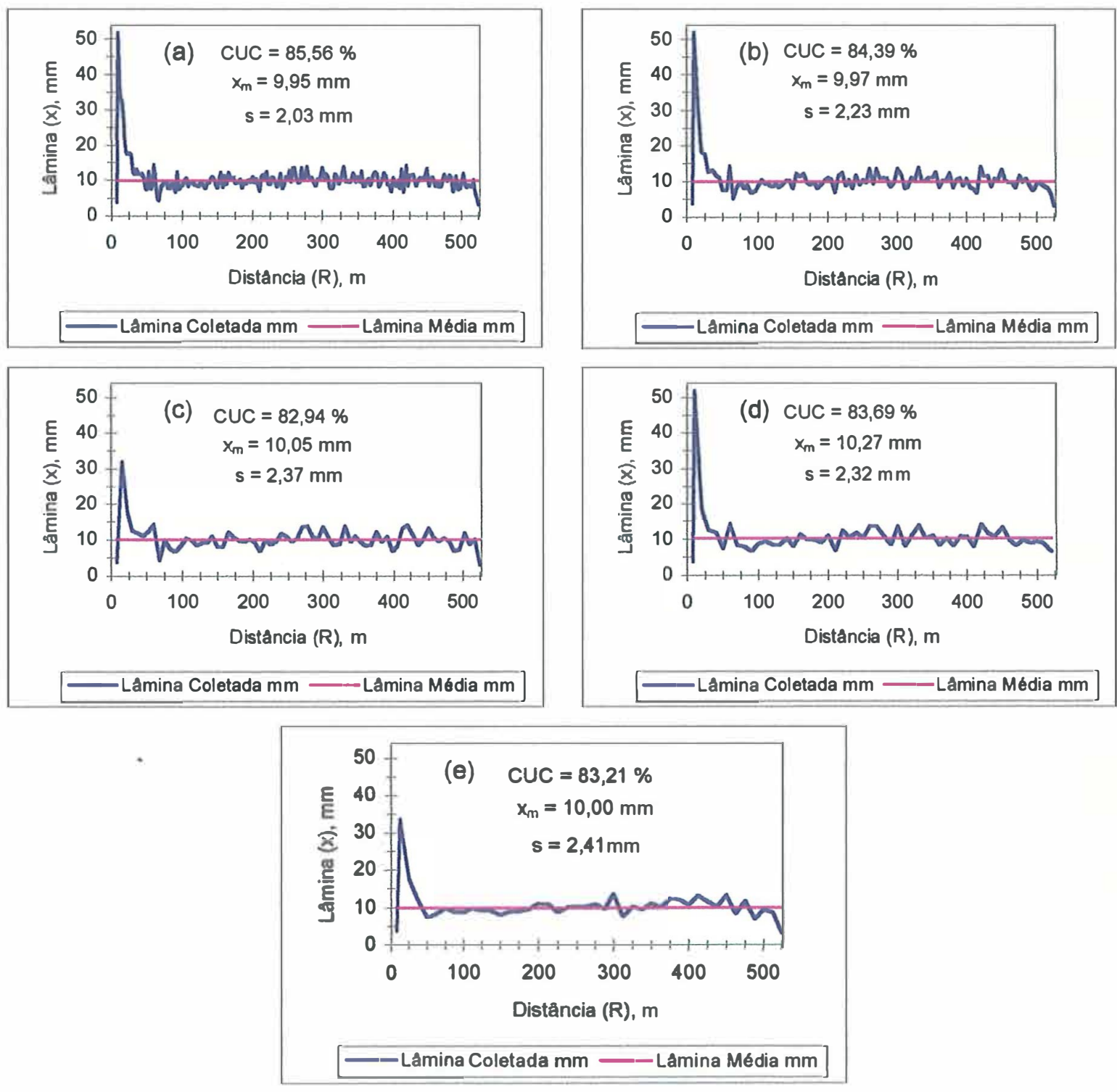

Figura 5 - Distribuição da água no teste 2A (4 linhas radiais de coletores), para os seguintes espaçamentos entre os coletores (a) 2,5 m, (b) 5,0 m, (c) 7,5 m, (d) $10,0 \mathrm{~m} \mathrm{e}(\mathrm{e}) 12,5 \mathrm{~m}$. 

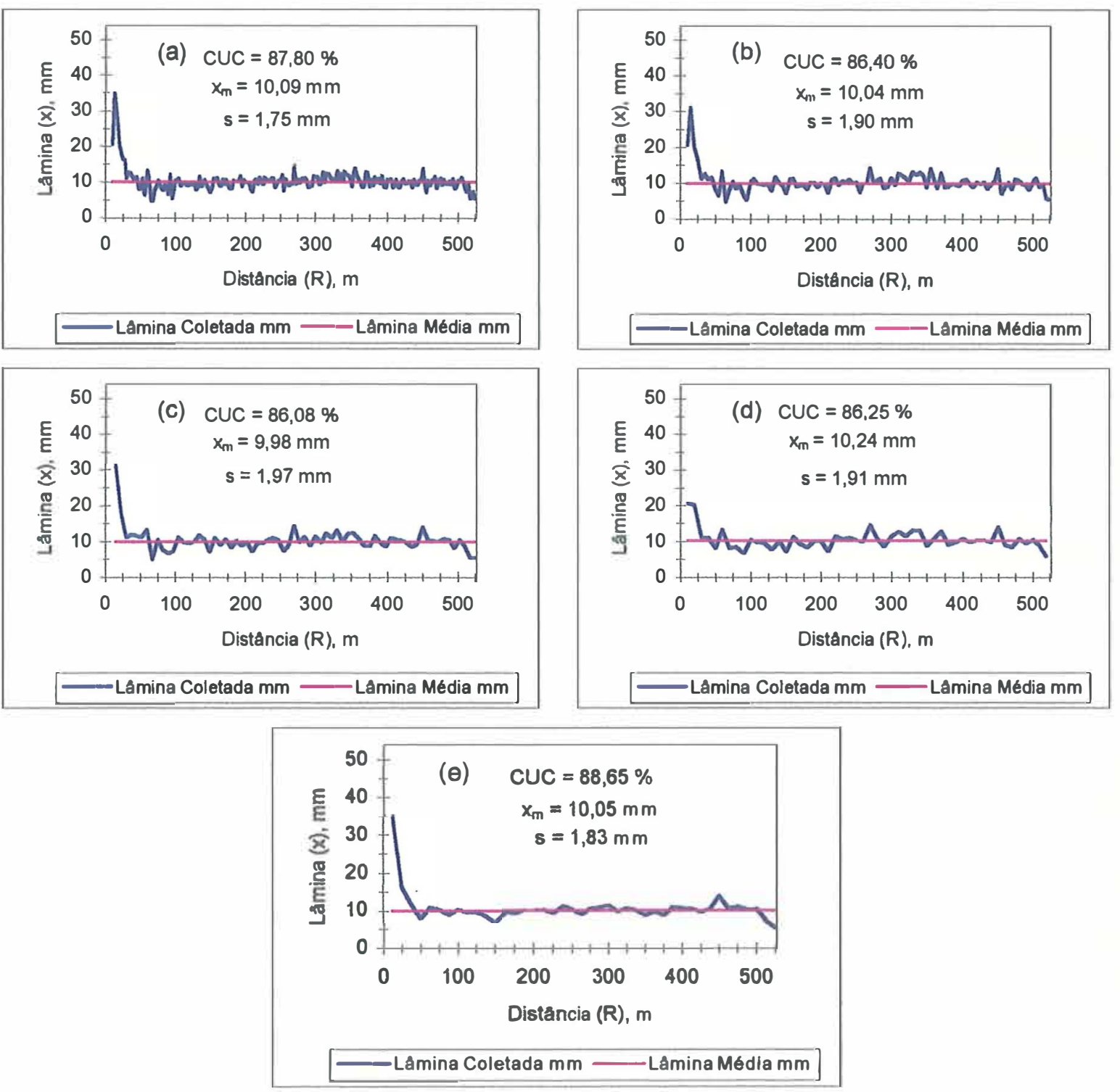

Figura 6 - Distribuição da água no teste 2B (4 linhas radiais de coletores), para os seguintes espaçamentos entre os coletores (a) 2,5 m, (b) 5,0 m, (c) 7,5 m, (d) $10,0 \mathrm{~m} \mathrm{e}$ (e) $12,5 \mathrm{~m}$. 

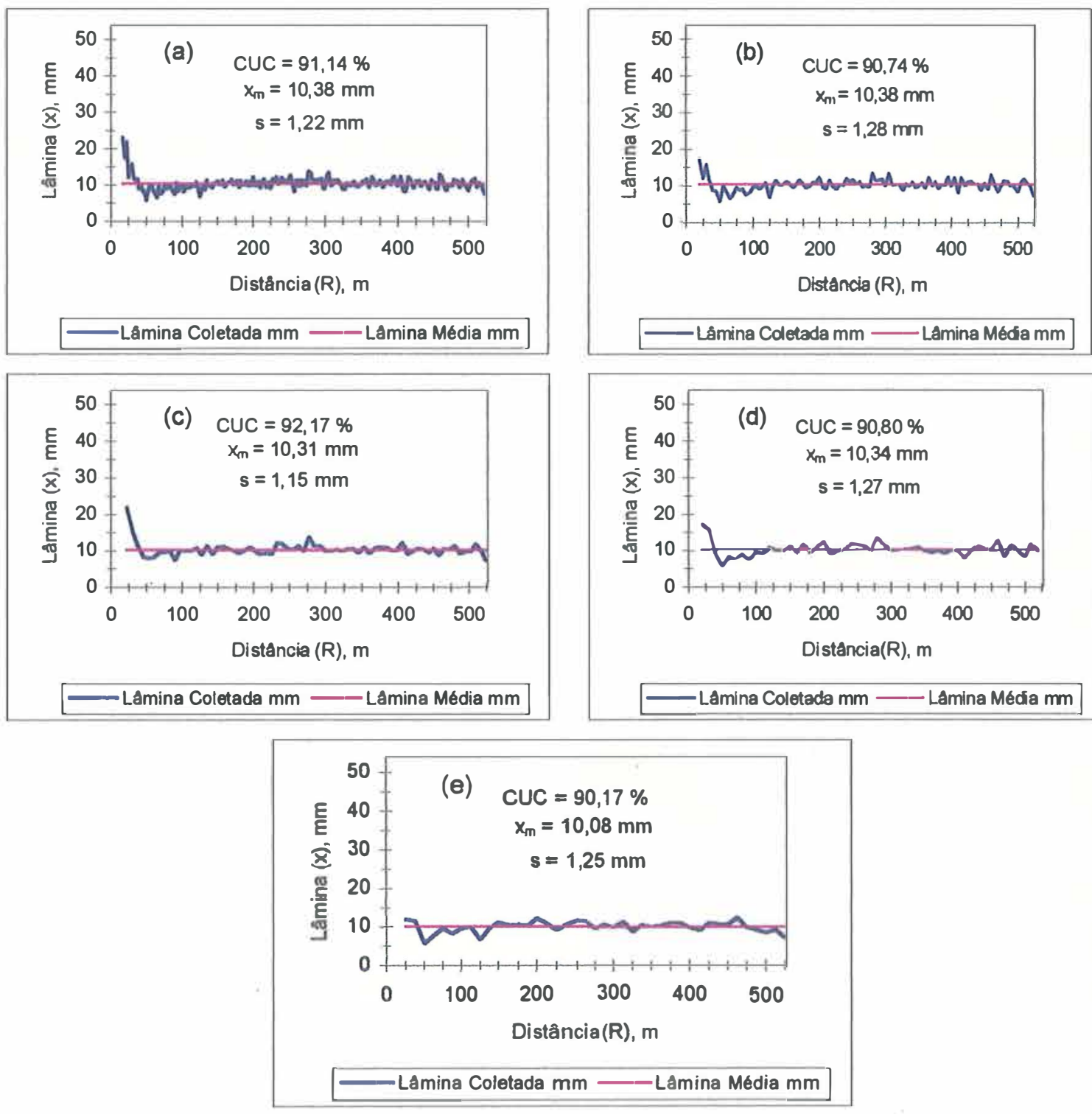

Figura 7 - Distribuição da água no teste 3A (4 linhas radiais de coletores), para os seguintes espaçamentos entre os coletores (a) 2,5 m, (b) 5,0 m, (c) 7,5 m, (d) $10,0 \mathrm{~m} \mathrm{e}(\mathrm{e}) 12,5 \mathrm{~m}$. 

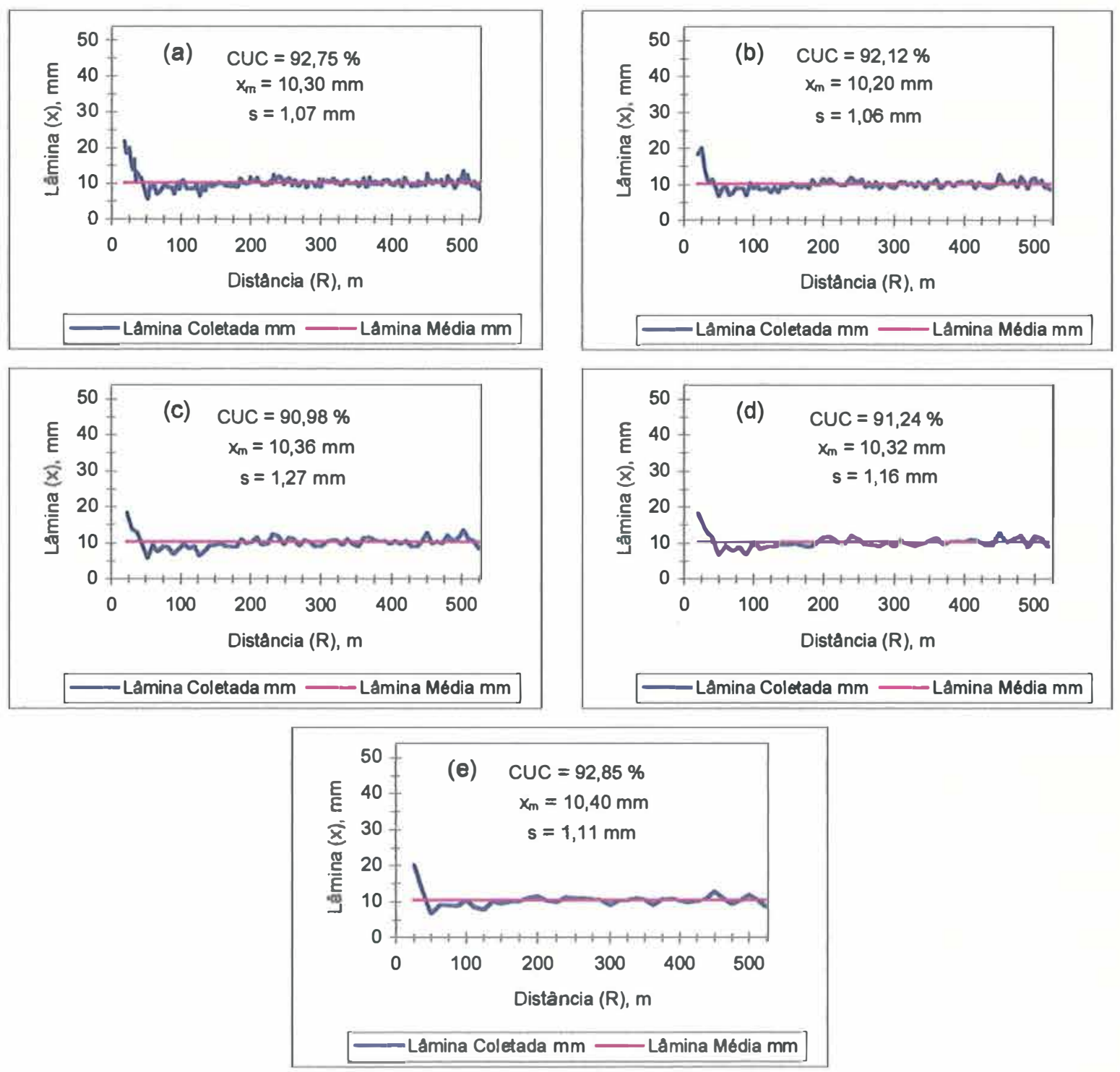

Figura 8 - Distribuição da água no teste 3B (4 linhas radiais de coletores), para os seguintes espaçamentos entre os coletores (a) 2,5 m, (b) 5,0 m, (c) 7,5 m, (d) $10,0 \mathrm{~m} \mathrm{e}$ (e) $12,5 \mathrm{~m}$. 

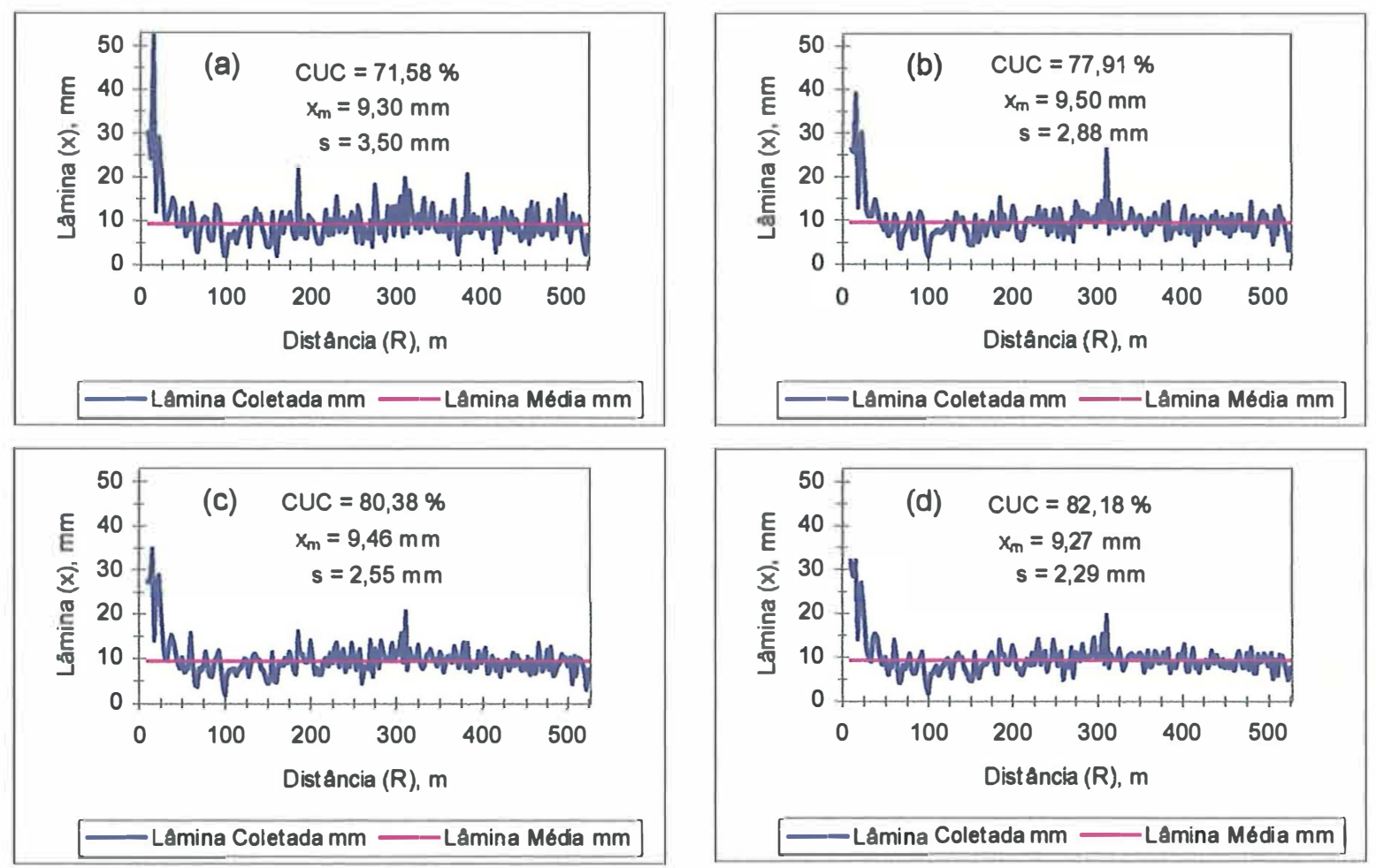

Figura 9 - Distribuição da água no teste $1 \mathrm{~A}$ (espaçamento de 2,5 m entre coletores), para (a) 1 linha radial, (b) 2 linhas radiais, (c) 3 linhas radiais e (d) 4 linhas radiais. 

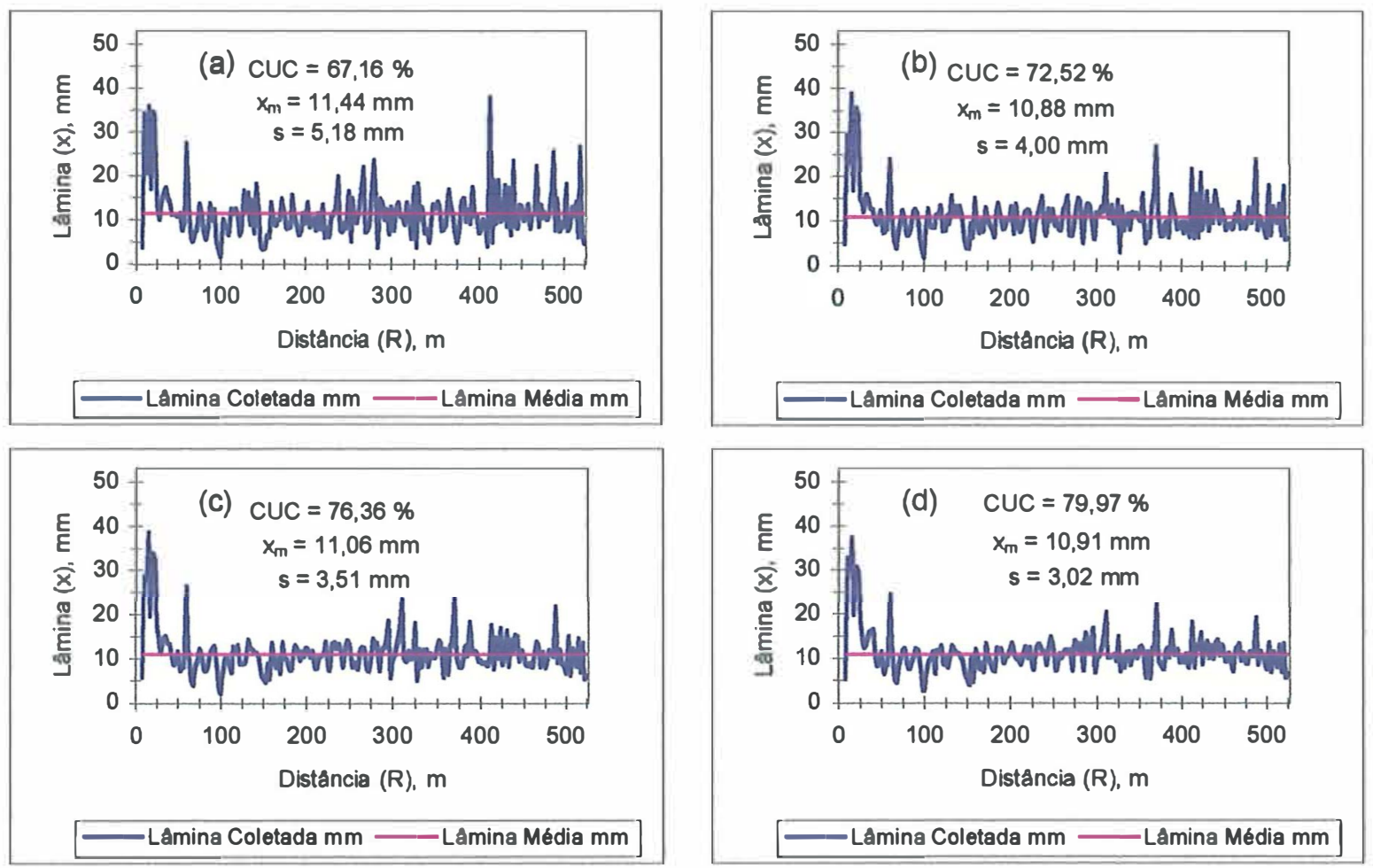

Figura 10 - Distribuição da água no teste 1B (espaçamento de 2,5 m entre coletores), para (a) 1 linha radial, (b) 2 linhas radiais, (c) 3 linhas radiais e (d) 4 linhas radiais. 

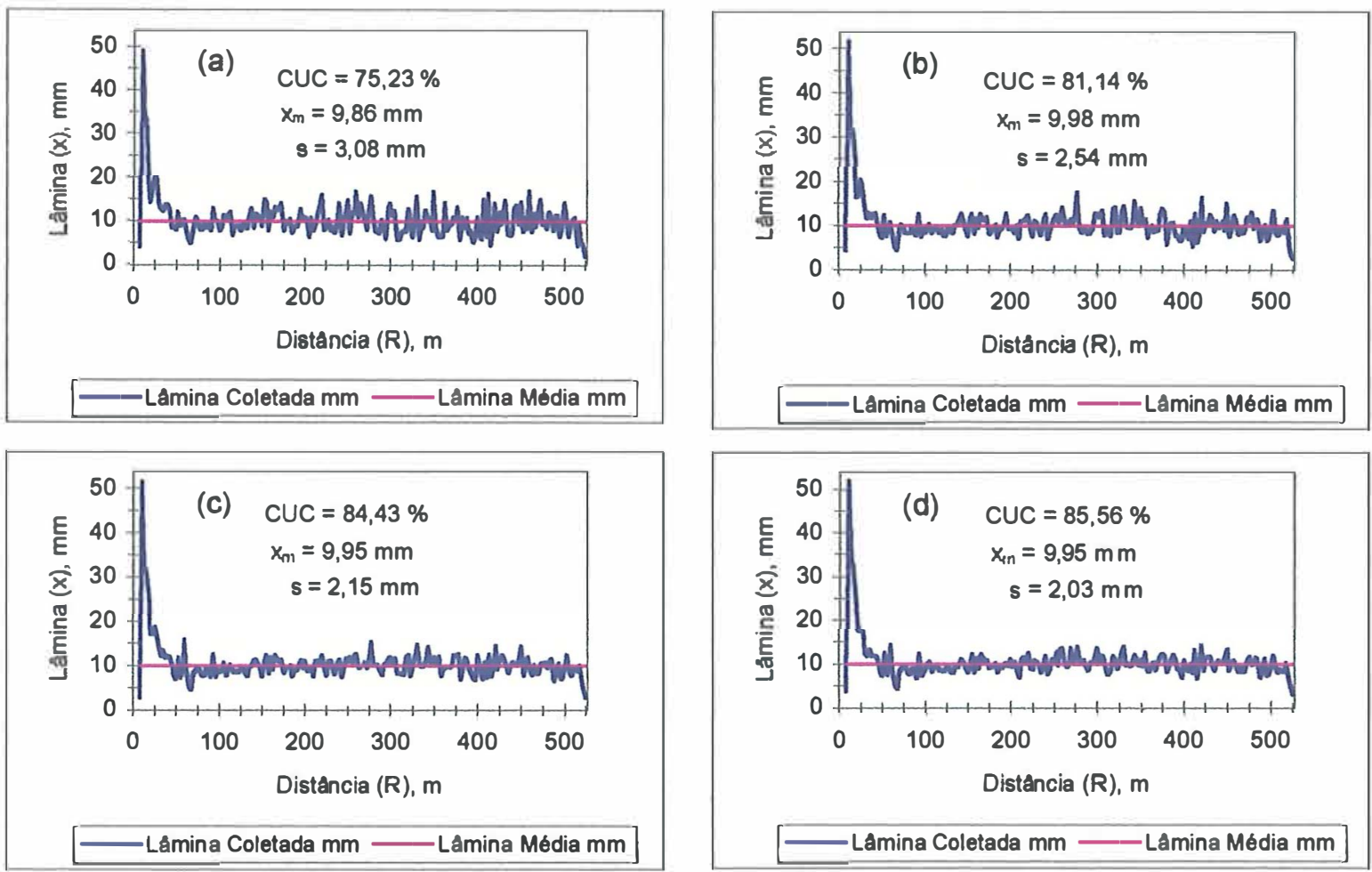

Figura 11 - Distribuição da água no teste 2A (espaçamento de 2,5 m entre coletores), para (a) 1 linha radial, (b) 2 linhas radiais, (c) 3 linhas radiais e (d) 4 linhas radiais. 

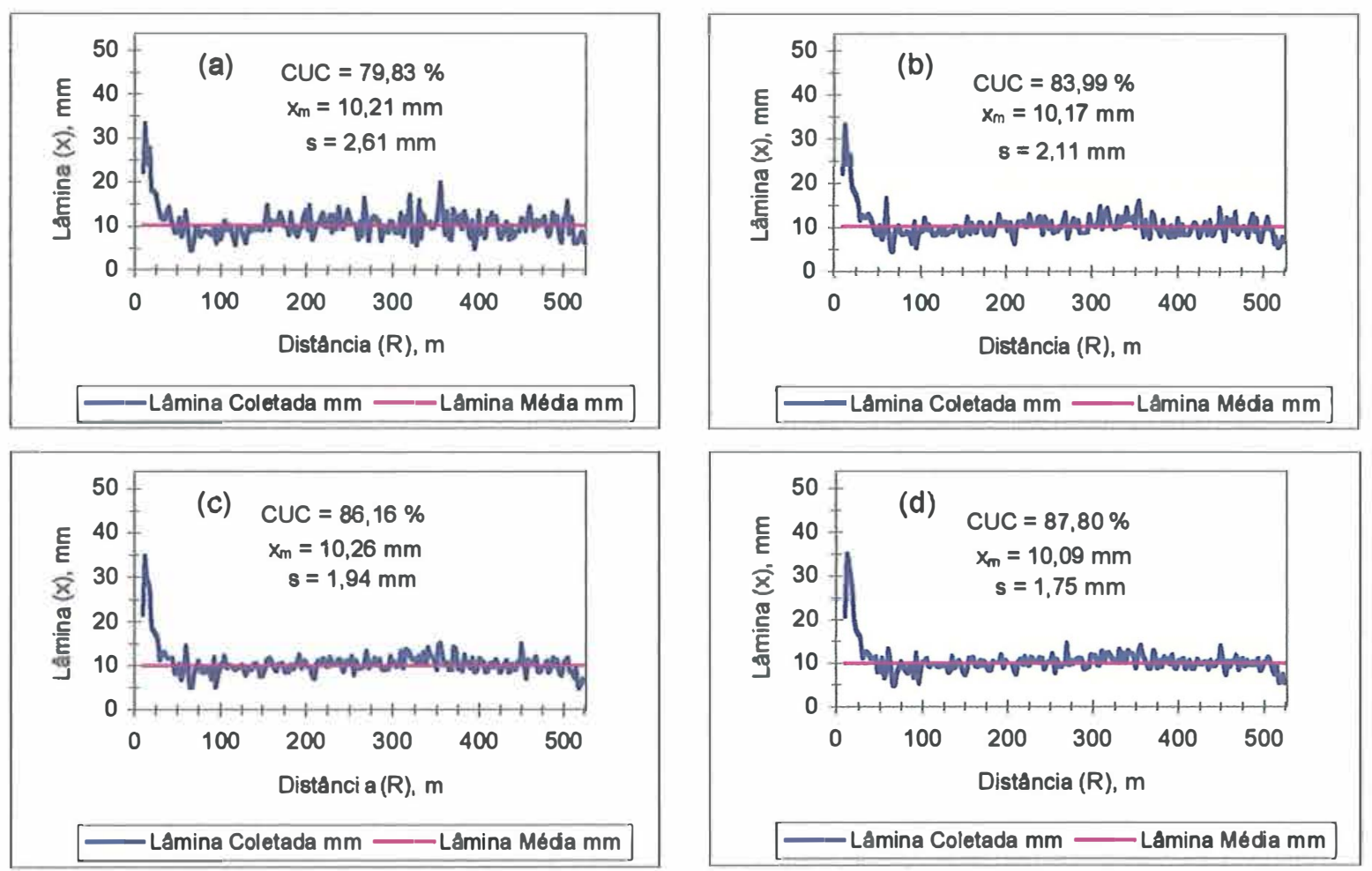

Figura 12 - Distribuição da água no teste 2B (espaçamento de 2,5 m entre coletores), para (a) 1 linha radial, (b) 2 linhas radiais, (c) 3 linhas radiais e (d) 4 linhas radiais. 

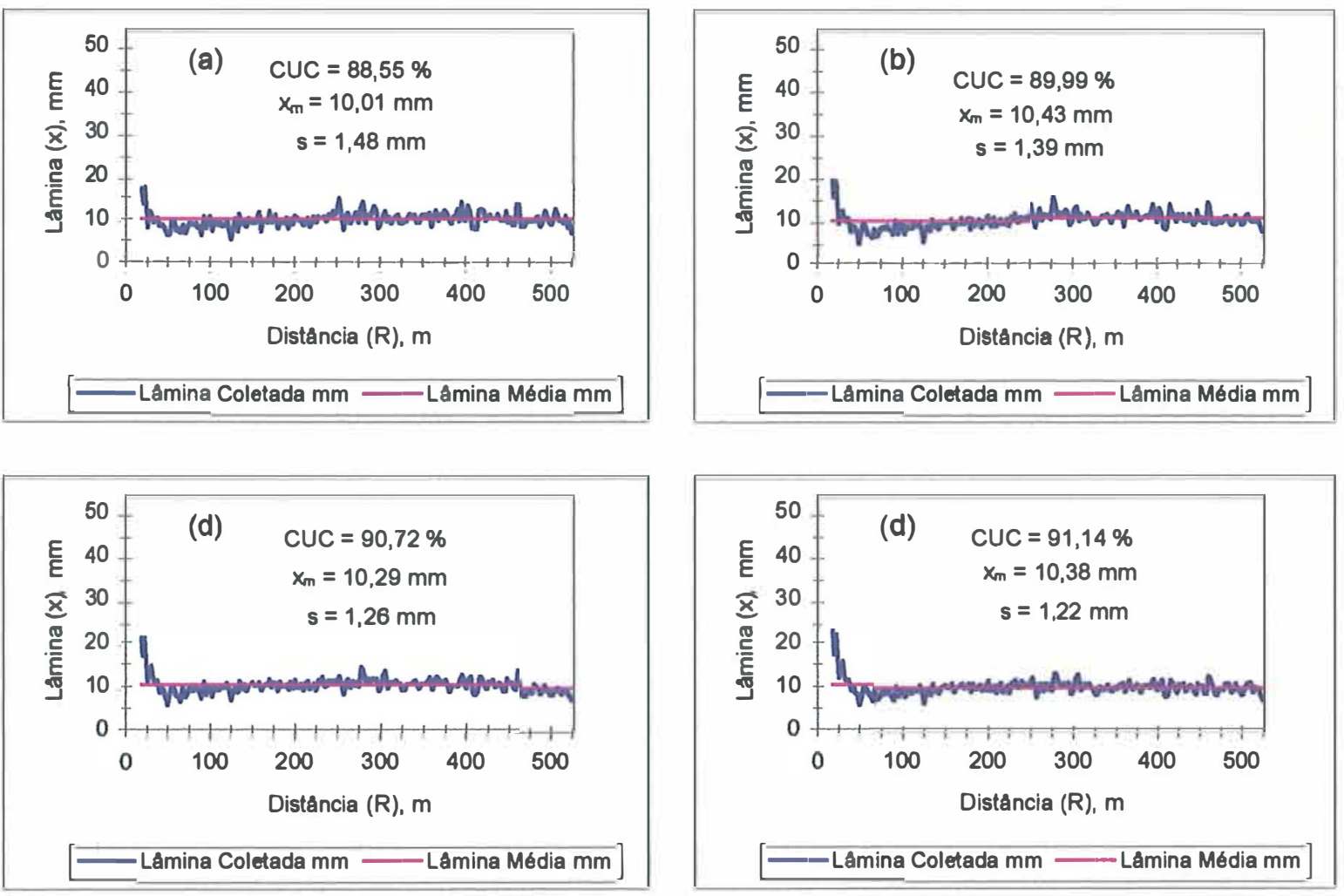

Figura 13 - Distribuição da água no teste 3A (espaçamento de 2,5 m entre coletores), para (a) 1 linha radial, (b) 2 linhas radiais, (c) 3 linhas radiais e (d) 4 linhas radiais. 

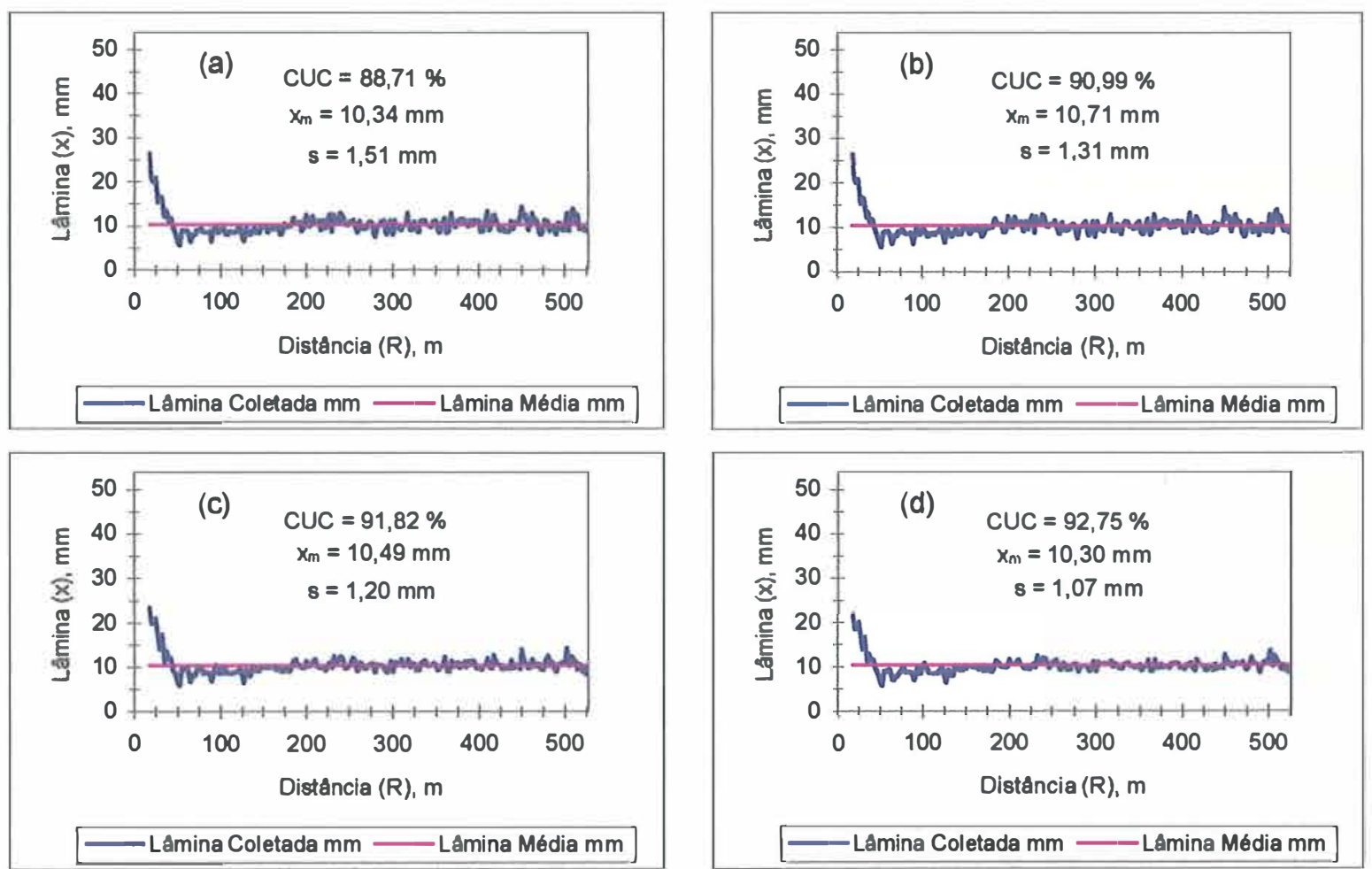

Figura 14 - Distribuição da água no teste 3B (espaçamento de 2,5 m entre coletores), para (a) 1 linha radial, (b) 2 linhas radiais, (c) 3 linhas radiais e (d) 4 linhas radiais. 


\section{1 - ESPAÇAMENTO ENTRE COLETORES}

No Quadro 4, são apresentados os valores médios de coeficiente de uniformidade de Christiansen (CUC) e os resultados da análise estatística, obtidos para cinco diferentes espaçamentos entre coletores, em 1, 2, 3 e 4 linhas radiais e com os emissores a $1,10 \mathrm{~m}, 1,65 \mathrm{~m}$ e 3,20 m em relação à seção de captação dos coletores.

O Quadro 5 mostra as variações dos valores médios de CUC, nos diferentes espaçamento entre coletores, em relação àqueles obtidos com espaçamento de $2,5 \mathrm{~m}$ entre coletores, para 1,2, 3 e 4 linhas radiais e com os emissores a 1,10 m, 1,65 m e 3,20 m em relação à seção de captação dos coletores.

Quadro 4 - Valores médios de CUC e resultados da análise estatística, em função do espaçamento entre os coletores, para 1, 2, 3 e 4 linhas radiais de coletores e três alturas de emissores em relação aos coletores ${ }^{1}$.

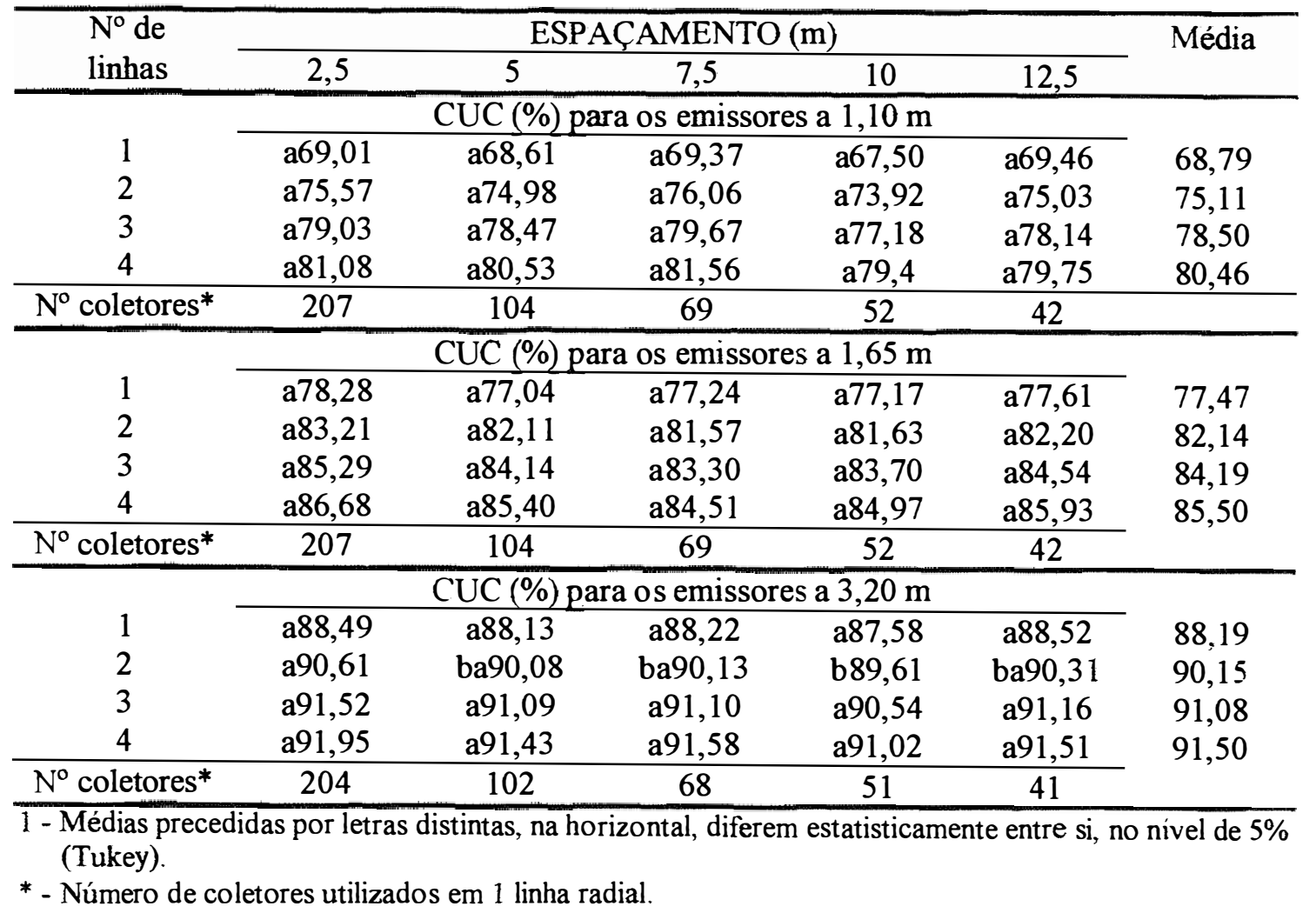


Quadro 5 - Variação dos valores médios de CUC, para os diferentes espaçamentos entre os coletores, em relação àqueles obtidos com espaçamento de $2,5 \mathrm{~m}$ entre os coletores, para 1, 2, 3 e 4 linhas radiais e três alturas dos emissores em relação aos coletores.

\begin{tabular}{|c|c|c|c|c|c|}
\hline \multirow{2}{*}{$\begin{array}{l}N^{\circ} \text { de } \\
\text { linhas }\end{array}$} & \multicolumn{5}{|c|}{ ESPAÇAMENTO (m) } \\
\hline & 2,5 & 5 & 7,5 & 10 & 12,5 \\
\hline & \multicolumn{5}{|c|}{ Variação do CUC, em \%, para os emissores a $1,10 \mathrm{~m}$} \\
\hline 1 & 0 & $-0,58$ & $+0,52$ & $-2,19$ & $+0,65$ \\
\hline 2 & 0 & $-0,78$ & $+0,64$ & $-2,18$ & $-0,71$ \\
\hline 3 & 0 & $-0,71$ & $+0,80$ & $-2,34$ & $-1,13$ \\
\hline \multirow[t]{2}{*}{4} & 0 & $-0,68$ & $+0,59$ & $-2,07$ & $-1,64$ \\
\hline & \multicolumn{5}{|c|}{ Variação do CUC, em \%, para os emissores a $1,65 \mathrm{~m}$} \\
\hline 1 & 0 & $-1,58$ & $-1,33$ & $-1,42$ & $-0,86$ \\
\hline 2 & 0 & $-1,32$ & - 1,97 & $-1,90$ & $-1,21$ \\
\hline 3 & 0 & $-1,35$ & $-2,33$ & $-1,86$ & $-0,88$ \\
\hline \multirow[t]{2}{*}{4} & 0 & $-0,86$ & $-1,21$ & $-0,88$ & $-0,86$ \\
\hline & \multicolumn{5}{|c|}{ Variação do CUC, em \%, para os emissores a 3,20 m } \\
\hline 1 & 0 & $-0,41$ & $-0,31$ & $-1,03$ & $+0,03$ \\
\hline 2 & 0 & $-0,58$ & $-0,53$ & $-1,10$ & $-0,33$ \\
\hline 3 & 0 & $-0,47$ & $-0,46$ & $-1,07$ & $-0,39$ \\
\hline 4 & 0 & $-0,57$ & $-0,40$ & $-1,01$ & $-0,48$ \\
\hline
\end{tabular}

\subsection{1 - Emissor a $1,10 \mathrm{~m}$}

Pelo teste de Tukey, no nível de probabilidade de $5 \%$, os valores de CUC não diferiram entre si, para os espaçamentos de 2,5 m, 5,0 m, 7,5 m, 10,0 m e 12,5 m, com os emissores a 1,10 m (Quadro 4).

Observa-se uma variação nos valores do desvio padrão em função do aumento do espaçamento entre coletores, conforme ilustram as Figuras 3 e 4 . Nas mesmas figuras, os espaçamentos de $12,5 \mathrm{~m}$ e $5,0 \mathrm{~m}$ entre coletores, respectivamente, apresentam o menor valor de desvio-padrão.

O espaçamento de 10,0 m entre os coletores apresentou maior dispersão dos valores de CUC para 1, 2, 3 e 4 linhas radiais, em relação àqueles obtidos no espaçamento de 2,5 m entre coletores. A quantificação dessa dispersão dos valores de CUC é mostrada no Quadro 5. A Figura 15 (a), que representa graficamente os valores de CUC do Quadro 4, evidencia essa dispersão de valores no espaçamento de 10,0 m. 
Os valores médios de CUC, nos cinco diferentes espaçamentos entre os coletores, para 1, 3 e 4 linhas radiais, estão mais próximos dos valores obtidos no espaçamento de 5,0 m entre coletores. Para 2 linhas radiais, o valor médio está mais próximo do valor obtido no espaçamento de 12,5 m, conforme ilustra o Quadro 4.

\subsection{2 - Emissor a $1,65 \mathrm{~m}$}

Pelo teste de Tukey, no nivel de probabilidade de $5 \%$, os valores de CUC não diferiram entre si, para os espaçamentos de $2,5 \mathrm{~m}, 5,0 \mathrm{~m}, 7,5 \mathrm{~m}, 10,0 \mathrm{~m}$ e $12,5 \mathrm{~m}$, na altura dos emissores de 1,65 $\mathrm{m}$ (Quadro 4).

Observa-se uma variação nos valores do desvio padrão em função do aumento do espaçamento entre os coletores, conforme ilustram as Figuras 5 e 6. Nessas mesmas figuras, os espaçamentos de 2,5 m entre coletores apresentam o menor valor de desviopadrão.

O espaçamento de 7,5 m entre coletores apresenta a maior dispersão dos valores de CUC, em relação àqueles obtidos no espaçamento de $2,5 \mathrm{~m}$, para 2, 3 e 4 linhas radiais (Quadro 5). Para 1 linha radial, a maior dispersão dos valores de CUC ocorre no espaçamento de 5,0 m entre os coletores. A Figura 15 (b), que representa graficamente os valores CUC do Quadro 4, evidencia tais dispersões.

Os valores médios de CUC, para 2, 3 e 4 linhas radiais, nos diferentes espaçamentos entre coletores, estão mais próximos dos valores obtidos no espaçamento de 5,0 m. Para 1 linha radial, o valor médio está mais próximo do valor obtido no espaçamento de $12,5 \mathrm{~m}$.

\subsection{3 - Emissor a 3,20 m}

Pelo teste de Tukey, no nível de probabilidade de $5 \%$, os valores de CUC diferiram entre si, para os espaçamentos de $2,5 \mathrm{~m}$ e $10,0 \mathrm{~m}$, somente para 2 linhas radiais de coletores. Para os demais números de linhas radiais, estatisticamente não houve diferenças entre os diversos espaçamentos entre coletores (Quadro 4). Esse 
resultado não seguiu a tendência dos valores apresentados no Quadro 4, para as alturas dos emissores de $1,10 \mathrm{~m}$ e $1,65 \mathrm{~m}$.

Observa-se uma variação nos valores do desvio-padrão, conforme ilustram as Figuras 7 e 8. Essas mesmas figuras, apresentam um menor desvio-padrão, respectivamente, para os espaçamentos de 7,5 $\mathrm{m}$ e 5,0 m entre coletores.
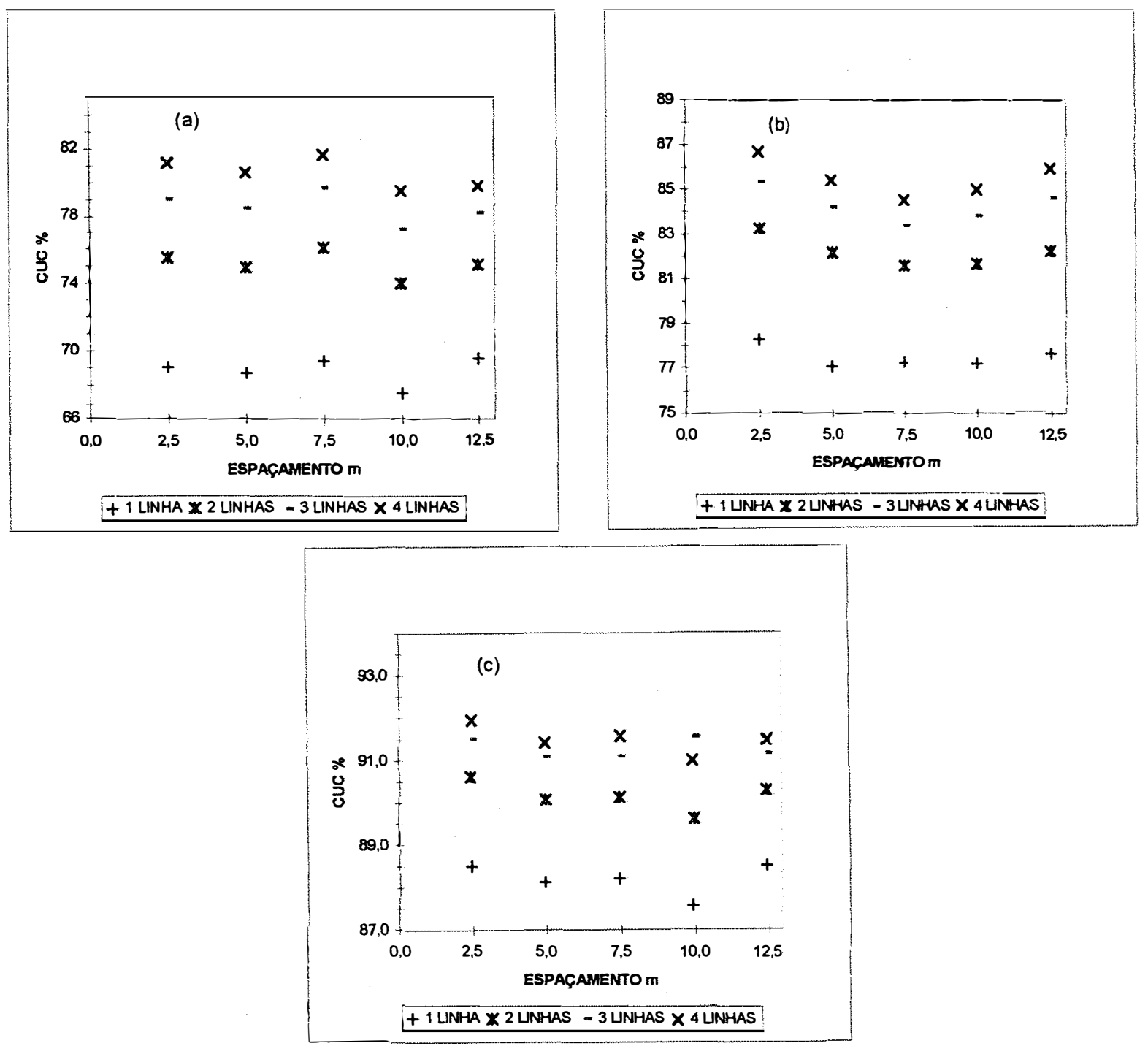

Figura 15 - Valores de CUC, para cinco espaçamentos diferentes entre os coletores, para 1, 2, 3 e 4 linhas radiais e três alturas dos emissores (a) $1,10 \mathrm{~m}$, (b) $1,65 \mathrm{~m}$ e (c) $3,20 \mathrm{~m}$ respectivamente. 
O espaçamento de 10,0 m entre coletores apresentou uma maior dispersão dos valores de CUC. O Quadro 5 salienta semelhante fato. A Figura 15 (c), que representa graficamente os valores de CUC do Quadro 4, para a altura de emissores de 3,20 m, evidencia a dispersão dos valores de CUC no espaçamento de $10,0 \mathrm{~m}$.

Os valores médios do CUC, nos diferentes espaçamentos entre coletores, estão mais próximos dos valores de CUC obtido no espaçamento de 7,5 m, para 1 e 2 linhas radiais. Para 3 e 4 linhas radiais, os valores médios estão mais próximos dos valores de CUC obtidos nos espaçamentos de 5,0 m e $12,5 \mathrm{~m}$, respectivamente.

\subsection{4 - Comparação entre as três alturas}

Para as três alturas estudadas, os valores de CUC, nos cinco diferentes espaçamentos, não diferiram estatisticamente entre si. Entretanto, deve-se observar que as avaliações foram realizadas com um equipamento cuja distribuição de água não revelou áreas de excesso e déficit de água bem caracterizadas.

Observa-se que o aumento do espaçamento entre coletores, somente ocasionou variações no perfil gráfico de distribuição da água do pivô central e nos valores do desvio-padrão. O perfil da lâmina de água modificou-se porque ocorreu a supressão de dados de volumes coletados com o aumento do espaçamento entre os coletores, ou seja, a diminuição do número de coletores utilizado no cálculo do CUC (Quadro 4). Consequentemente, a utilização de maiores espaçamentos prejudica a análise do perfil gráfico de distribuição da água, mas não interfere no cálculo do CUC, conforme ilustram as Figuras 3, 4, 5, 6, 7, 8 e o Quadro 4.

Os valores do desvio-padrão alteraram-se, em relação àquele obtido para o espaçamento de 2,5 m entre coletores, devido, também, à supressão dos dados de volume coletado. Se os volumes suprimidos forem os de valores discrepantes, o desviopadrão diminui, conforme ilustram as Figuras 3 (e), 4 (b), 7 (c) e 8 (b). Caso contrário, o valor do desvio-padrão poderá aumentar, conforme ilustram as Figuras 3 (d), 4 (e), 5 (e), 6 (c), 7 (b) e 8 (c). 
De acordo com os dados obtidos no Quadro 5, as menores variações dos valores de CUC, nos diferentes espaçamentos entre coletores, ocorreu com os emissores na altura de $3,20 \mathrm{~m}$

As Figuras 3, 4, 5, 6, 7 e 8 indicam uma variação mínima nas lâminas médias, nos cinco espaçamentos entre os coletores. Esses resultados estão compatíveis com aqueles apresentados por Davis (1966), D’Assunpção (1990) e Bremond \& Molle (1995).

\section{2 - NÚMERo DE LiNHAS RADIAIS DE COLETORES}

No Quadro 6, são apresentados os valores médios de CUC e os resultados da análise estatística obtidos para 1, 2, 3 e 4 linhas radiais, em cinco diferentes espaçamentos entre coletores, e com os emissores a 1,10 m, 1,65 m e 3,20 m em relação à seção de captação dos coletores. Devido a homogeneidade de variância, entre as repetições, ser baixa, foi necessário a transformação logarítmica desses valores. Os valores, entre parênteses, representam a média das repetições transformadas.

O Quadro 7 mostra as variações dos valores médios de CUC, para 1, 2, 3 e 4 linhas radiais, em relação àqueles obtidos com 1 linha radial, nos diferentes espaçamento entre coletores e com os emissores a $1,10 \mathrm{~m}, 1,65 \mathrm{~m}$ e 3,20 m em relação à seção de captação dos coletores.

\subsection{1 - Emissor a $1,10 \mathrm{~m}$}

Pelo teste de Tukey, no nível de probabilidade de $5 \%$, nos espaçamentos de 2,5 $\mathrm{m}, 7,5 \mathrm{~m}, 10,0 \mathrm{~m}$ e $12,5 \mathrm{~m}$ entre coletores, os valores de CUC diferiram entre si, somente para 1 linha radial de coletores. Esse resultado não apresentou diferença significativa ao utilizar-se 2,3 ou 4 linhas radiais, nos respectivos espaçamentos. Para o espaçamento de 5,0 m, os valores de CUC diferiram entre si para 1 e 2, 1 e 3,1 e 4, 2 e 3 e 2 e 4 linhas radiais (Quadro 6). Esse resultado, somente não apresentou diferença significativa para 3 e 4 linhas radiais. 
Quadro 6 - Valores médios de CUC e resultados da análise estatística, em função do número de linhas de coletores para cinco diferentes espaçamentos entre os coletores e três alturas do emissor em relação aos coletores ${ }^{1}$.

\begin{tabular}{|c|c|c|c|c|c|}
\hline \multirow{2}{*}{$\begin{array}{l}\mathrm{N}^{\circ} \mathrm{de} \\
\text { linhas }\end{array}$} & \multicolumn{5}{|c|}{ ESPAÇAMENTO (m) } \\
\hline & 2,5 & 5 & 7,5 & 10 & 12,5 \\
\hline & \multicolumn{5}{|c|}{ CUC (\%) para os emissores a $1,10 \mathrm{~m}$} \\
\hline 1 & a69,01 (1,84) & a68,61 $(1,84)$ & a69,37 (1,84) & $\mathrm{a} 67,50(1,83)$ & a69,46 (1,90) \\
\hline 2 & $75,57(1,88)$ & b74,98 $(1,87)$ & b76,06 $(1,88)$ & b73,92 (1,87) & b75,03 (1,89) \\
\hline 3 & b79,03 $(1,90)$ & c78,47 $(1,89)$ & b79,67 (1,90) & b77,18 (1,89) & b78,14 (1,87) \\
\hline 4 & $\mathrm{~b} 81,08(1,91)$ & c $80,53(1,91)$ & b81,56 (1,91) & b79,40 (1,90) & b79,75 (1,84) \\
\hline Média & 76,17 & 75,65 & 76,67 & 74,50 & 75,60 \\
\hline & \multicolumn{5}{|c|}{ CUC (\%) para os emissores a $1,65 \mathrm{~m}$} \\
\hline 1 & a78,28 (1,89) & a77,04 (1,87) & a77,24 (1,89) & a77, $17(1,89)$ & a77,61 (1,89) \\
\hline 2 & b83,21 $(1,92)$ & b82,11 $(1,91)$ & b81,57 (1,91) & b81,63 (1,91) & b82,20 (1,91) \\
\hline 3 & b85,29 (1,93) & b84, $14(1,92)$ & b83,30 (1,92) & b83,70 (1,92) & $\mathrm{b} 84,54(1,93)$ \\
\hline 4 & b86,68 (1,94) & $\mathrm{b} 85,40(1,93)$ & b84,51 (1,93) & b84,97 (1,93) & $\mathrm{b} 85,93(1,93)$ \\
\hline Média & 83,37 & 82,17 & 81,66 & 81,87 & 82,57 \\
\hline & \multicolumn{5}{|c|}{ CUC (\%) para os emissores a $3,20 \mathrm{~m}$} \\
\hline 1 & a88,49 (1,95) & a88,13 (1,94) & $\mathrm{a} 88,22(1,94)$ & $\mathrm{a} 87,58(1,94)$ & $\mathrm{a} 88,52(1,95)$ \\
\hline 2 & b90,61 $(1,96)$ & b90,08 $(1,95)$ & b90,13 $(1,95)$ & b89,61 (1,95) & b90,31 (1,96) \\
\hline 3 & b91,52 (1,96) & b91,09 $(1,95)$ & b91,10 $(1,96)$ & b90,54 (1,96) & b91,16 $(1,96)$ \\
\hline 4 & b91,95 $(1,96)$ & b91,43 $(1,96)$ & b91,58 $(1,96)$ & b91,02 $(1,96)$ & b91,51 $(1,96)$ \\
\hline Média & $90, \overline{64}$ & 90,18 & 90,26 & 89,69 & 90,38 \\
\hline
\end{tabular}

1 - Médias precedidas por letras distintas, na vertical, diferem estatisticamente entre si a 5\% (Tukey). ( ) - Médias das repetições transformadas (logaritmo).

O aumento dos valores de CUC, nos cinco diferentes espaçamentos, ocorreu em função do aumento do número de linhas radiais. Isso pode ser evidenciado pela Figura 16 (a), que representa graficamente os valores de CUC do Quadro 6.

De acordo com as Figuras 9 e 10, observa-se que a diminuição do número de linhas radiais ocasiona uma variação nos valores do desvio-padrão em relação àquele obtido com 4 linhas radiais. Observa-se que o desvio-padrão apresenta uma tendência característica de diminuir em função do aumento do número de linhas radiais. A maior variação dessa medida de dispersão ocorre com a mudança de 1 para 2 linhas radiais. Consequentemente, a maior variação nos valores de CUC ocorre também na mudança de 1 para 2 linhas radiais, como salientam o Quadro 6 (teste de Tukey) e o Quadro 7. 
As médias dos valores CUC das linhas radiais, nos cinco diferentes espaçamentos, estão mais próximas dos valores de CUC obtidos com 2 linhas radiais, conforme dados do Quadro 6.

Quadro 7 - Variação dos valores médios de CUC, em \%, para 1, 2, 3 e 4 linhas radiais, em relação àqueles obtidos com 1 linha radial, em diferentes espaçamentos entre os coletores e três alturas dos emissores.

\begin{tabular}{|c|c|c|c|c|c|c|}
\hline \multirow{2}{*}{$\begin{array}{l}\mathrm{N}^{\circ} \text { de } \\
\text { linhas }\end{array}$} & \multicolumn{5}{|c|}{ ESPAÇAMENTO } & \multirow{2}{*}{$\begin{array}{c}\mathrm{N}^{\circ} \text { de } \\
\text { coletores* }\end{array}$} \\
\hline & 2,5 & 5 & 7,5 & 10 & 12,5 & \\
\hline \multicolumn{7}{|c|}{ Variação do CUC, em \%, para os emissores a $1,10 \mathrm{~m}$} \\
\hline 1 & 0 & 0 & 0 & 0 & 0 & 207 \\
\hline 2 & $+8,68$ & $+8,50$ & $+8,80$ & $+8,69$ & $+7,42$ & 414 \\
\hline 3 & $+12,68$ & $+12,57$ & $+12,93$ & $+12,54$ & $+11,11$ & 621 \\
\hline 4 & $+14,89$ & $+14,80$ & $+14,95$ & $+14,99$ & $+12,90$ & 828 \\
\hline \multicolumn{7}{|c|}{ Variação do CUC, em \%, para os emissores a $1,65 \mathrm{~m}$} \\
\hline 1 & 0 & 0 & 0 & 0 & 0 & 207 \\
\hline 2 & $+5,92$ & $+6,17$ & $+5,31$ & $+5,46$ & $+5,58$ & 414 \\
\hline 3 & $+8,22$ & $+8,44$ & $+7,27$ & $+7,80$ & $+8,20$ & 621 \\
\hline 4 & $+9,69$ & $+9,79$ & $+8,60$ & $+9,18$ & $+9,68$ & 828 \\
\hline \multicolumn{7}{|c|}{ Variação do CUC, em \%, para os emissores a 3,20 m } \\
\hline 1 & 0 & 0 & 0 & 0 & 0 & 204 \\
\hline 2 & $+2,34$ & $+2,16$ & $+2,12$ & $+2,27$ & $+1,98$ & 408 \\
\hline 3 & $+3,31$ & $+3,25$ & $+3,16$ & $+3,27$ & $+2,90$ & 612 \\
\hline 4 & $+3,76$ & $+3,61$ & $+3,67$ & $+3,78$ & $+3,27$ & 816 \\
\hline
\end{tabular}

* - Número de coletores utilizados para o espaçamento de $2,5 \mathrm{~m}$ entre coletores

\subsection{2 - Emissor a $1,65 \mathrm{~m}$}

Pelo teste de Tukey, no nível de probabilidade de 5\%, nos cinco espaçamentos entre os coletores, os valores de CUC diferiram entre si, para 1 e 2,1 e 3 e 1 e 4 linhas radiais (Quadro 6). De acordo com esses resultados, não há diferença significativa ao utilizar-se 2, 3 ou 4 linhas radiais.

O aumento nos valores de CUC, nos cinco diferentes espaçamentos, ocorreu em função do aumento do número de linhas radiais. Isso pode ser evidenciado pela Figura 16 (b), que representa graficamente os valores do CUC no Quadro 6.

Nas Figuras 11 e 12, observa-se que a diminuição do número de linhas radiais ocasiona um aumento nos valores do desvio-padrão em relação àqueles obtidos com 4 
linhas radiais. Segundo as mesmas figuras, observa-se que os valores do desvio-padrão apresentam uma tendência característica de diminuir, em função do aumento do número de linhas radiais. A maior variação dessa medida de dispersão ocorre com a mudança de 1 para 2 linhas radiais. Consequentemente, a maior variação nos valores de CUC ocorre na mudança de 1 para 2 linhas radiais, como salientam o Quadro 6 (teste de Tukey) e o Quadro 7.

O aumento do número de linhas radiais proporciona uma menor variação na lâmina coletada, do meio para o final do pivô central, conforme ilustram as Figuras $11 \mathrm{e}$ 12.

As médias dos valores CUC das linhas radiais, nos cinco espaçamentos diferentes, estão mais próximas dos valores de CUC obtidos com 2 linhas radiais, conforme dados do Quadro 6.

\subsection{3 - Emissor a 3,20 m}

Pelo teste de Tukey, no nível de probabilidade de 5\%, nos cinco espaçamentos entre coletores, os valores de CUC diferiram entre si, para 1 e 2,1 e 3 e 1 e 4 linhas radiais. De acordo com esses resultados, não há diferença significativa ao utilizar-se 2, 3 ou 4 linhas radiais (Quadro 6).

O aumento dos valores de CUC, nos cinco diferentes espaçamentos, ocorreu em função do aumento do número de linhas radiais. Isso pode ser evidenciado pela Figura 16 (c), que representa graficamente os valores de CUC do Quadro 6.

Nas Figuras 13 e 14, observa-se que a redução do número de linhas radiais ocasiona uma variação nos valores do desvio-padrão em relação àqueles obtidos com 4 linhas radiais. 

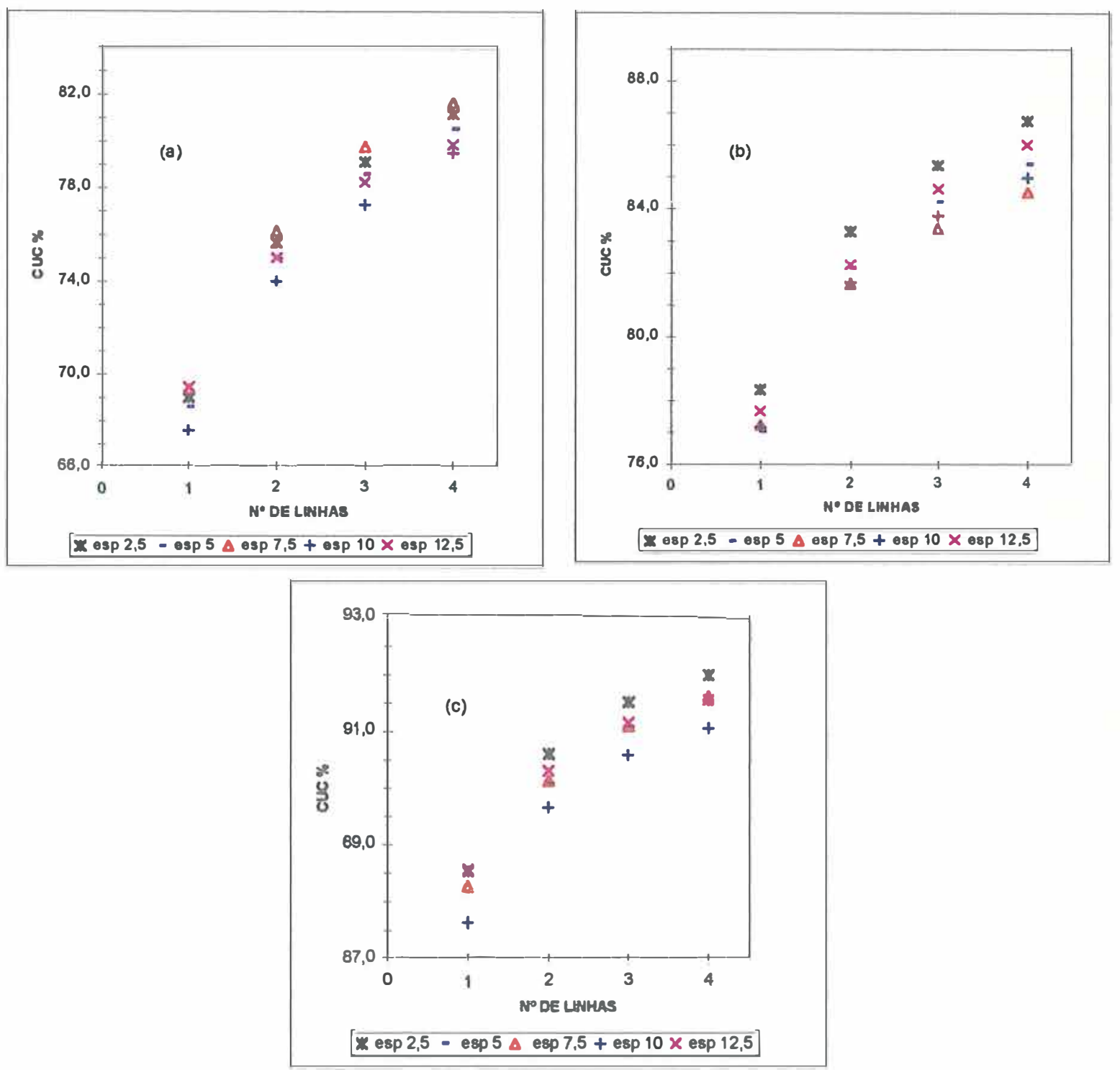

Figura 16 - Valores de CUC para 1, 2, 3 e 4 linhas radiais, cinco espaçamentos diferentes entre coletores e três alturas dos emissores (a) $1,10 \mathrm{~m}$, (b) 1,65 $\mathrm{m} \mathrm{e}(\mathrm{c}) 3,20 \mathrm{~m}$. 
O desvio-padrão apresenta uma tendência característica de diminuir, em função do aumento do número de linhas radiais. A maior variação dessa medida de dispersão ocorre com a mudança de 1 para 2 linhas radiais. Consequentemente, a maior variação nos valores de CUC ocorre na mudança de 1 para 2 linhas radiais, como salientam o Quadro 6 (teste de Tukey) e o Quadro 7.

O aumento no número de linhas radiais proporciona uma menor variação na lâmina coletada, do meio para o fim do pivô central, conforme ilustram as Figuras 13 e 14.

As médias dos valores CUC das linhas radiais, nos cinco diferentes espaçamentos, estão mais próximas dos valores de CUC obtidos com 2 linhas radiais, conforme dados do Quadro 6.

\subsection{4 - Comparação entre as três alturas}

Para as três alturas estudadas, os valores de CUC, diferiram estatisticamente entre si, somente para 1 linha radial. Não houve diferença estatística entre os valores de CUC para 2, 3 e 4 linhas radiais.

No Quadro 7, observa-se que em função do aumento da altura dos emissores, ocorre uma menor variação nos valores de CUC. Isso ocorre porque, com o aumento da altura dos emissores, o diâmetro molhado torna-se maior (Quadro 3), aumentando a área de recobrimento dos emissores e a uniformidade do sistema, e reduzindo a influência do número de linhas radiais no cálculo dos valores de CUC.

A Figura 17 ilustra o aumento dos valores de CUC em função do aumento do número de linhas radiais, principalmente na mudança de 1 para 2 linhas radiais. Nessa figura, observa-se que ocorre uma aproximação dos valores de CUC, em função do aumento do número de linhas radiais para as três alturas dos emissores. Observa-se, também, que, para uma mesma altura de emissor, a redução do número de linhas radiais ocasiona uma variação maior nos valores de CUC do que o aumento do espaçamento entre coletores. Isto ficou evidenciado na Figura 17 (a), (b), (c), (d) e (e).

Nas Figuras 9, 10, 11, 12, 13 e 14, observa-se que com o aumento do número de linhas radiais, diminuiu a variação da lâmina coletada do meio para o fim do pivô 
central e, consequentemente, o desvio-padrão. Isso ocorre porque, ao aumentar o número de linhas radiais, o volume de água coletado em um determinado ponto distante da base do pivô será somado ao volume de água de outro coletor, no mesmo ponto distante da base do pivô, mas em uma outra linha radial e assim por diante. Através da média aritmética da soma dos volumes, obtém-se um valor médio do volume coletado num determinado ponto distante da base do pivô. Esse valor será utilizado no cálculo da lâmina coletado nesse determinado ponto. Assim, volumes discrepantes coletados no momento em que ocorreram alguns distúrbios como rajadas de vento, desalinhamento do equipamento pivô central e vazamentos, são diluídos. Isso evidencia a importância do uso de mais de uma linha de coletores nas avaliações de desempenho, aumentando a precisão do valor do CUC obtido.

Em função do aumento do número de linhas radiais, para os emissores a $1,10 \mathrm{~m} \mathrm{e}$ 1,65 m, os valores de CUC, nos cinco espaçamentos tendem a dispersar, em relação ao uso de apenas 1 linha radial (Figura 16 a e b). Isso ocorre devido ao aumento da precisão que se obtém no cálculo dos valores de CUC, com o aumento do número de linhas radiais. Para o emissor a $3,20 \mathrm{~m}$, essa dispersão dos valores de CUC, para os cinco espaçamentos, não é tão caracterizada, pois nessa altura dos emissores, o equipamento apresenta a melhor uniformidade de distribuição de água, diminuindo a influência do número de linhas radiais no cálculo dos valores de CUC.

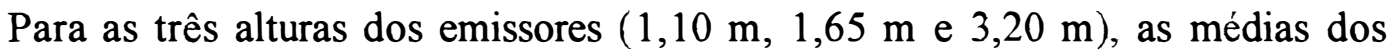
valores de CUC das linhas radiais, nos cinco espaçamentos distintos entre coletores, estão mais próximos dos valores de CUC obtidos com 2 linhas radiais.

\section{3 - AltURA DOS EMISSORES}

O Quadro 8 apresenta os valores médios de CUC e os resultados da análise estatística, obtidos em 3 alturas distintas dos emissores, em cinco espaçamentos diferentes entre coletores para 1, 2, 3 e 4 linhas radiais. 

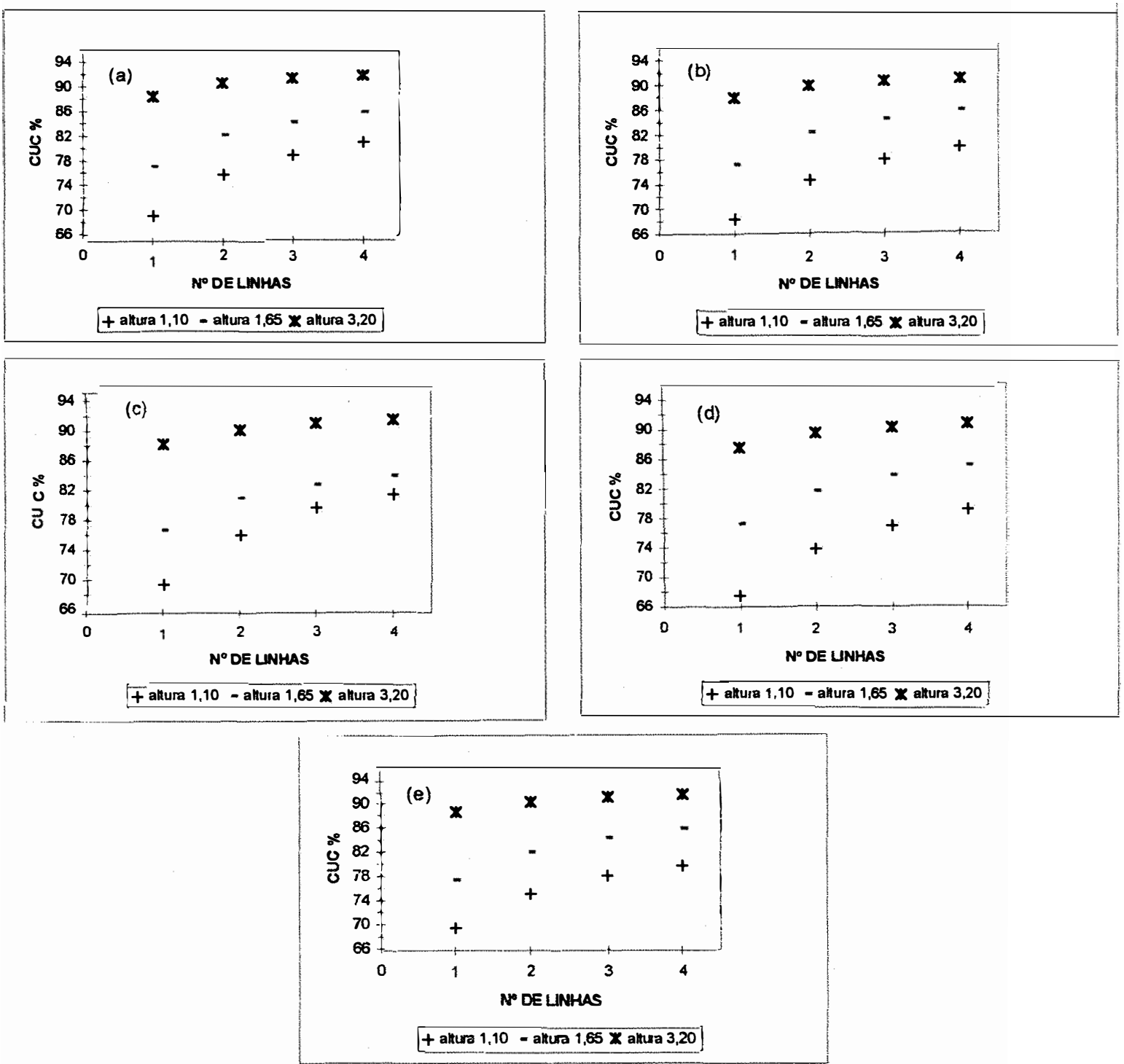

Figura 17 - Valores de CUC para 1, 2, 3 e 4 linhas radiais e três alturas diferentes dos emissores, para os espaçamentos entre os coletores (a) 2,5 m, (b) 5,0 m, (c) $7,5 \mathrm{~m}$, (d) $10,0 \mathrm{~m} \mathrm{e}(\mathrm{e}) 12,5 \mathrm{~m}$.

\subsection{1 - Uma, Duas e Três Linhas Radiais}

Pelo teste de Tukey, no nível de probabilidade de $5 \%$, os valores de CUC diferiram entre si, nas 3 alturas dos emissores em relação à superfície de captação dos 
coletores, para 1, 2 e 3 linhas radiais (Quadro 8). A Figura 18 (a), (b) e (c), que representa graficamente os dados do Quadro 8, ilustra o aumento dos valores de CUC, em função do aumento da altura dos emissores. Os maiores valores de CUC são observados na altura de 3,20 m dos emissores em relação à seção de captação dos coletores.

Quadro 8 - Valores médios de CUC e resultado da análise estatística, em função da altura dos emissores para cinco diferentes espaçamentos e 1, 2, 3 e 4 linhas radiais'.

\begin{tabular}{|c|c|c|c|c|}
\hline \multirow[t]{2}{*}{ Espaçamento } & \multicolumn{3}{|c|}{ ALTURA DOS EMISSORES } & \multirow[t]{2}{*}{ Média } \\
\hline & 1,10 & 1,65 & 3,20 & \\
\hline \multicolumn{5}{|c|}{ Valores de CUC (\%) para 1 linha radial } \\
\hline 2,5 & $\mathrm{a} 69,01$ & b78,28 & $\mathrm{c} 88,49$ & 78,59 \\
\hline 5 & a68,61 & b77,04 & $\mathrm{c} 88,13$ & 77,93 \\
\hline 7,5 & a69,37 & b77,24 & $\mathrm{c} 88,22$ & 78,28 \\
\hline 10 & $\mathrm{a} 67,50$ & b77, 17 & $\mathrm{c} 87,58$ & 77,42 \\
\hline 12,5 & a69,46 & b77,61 & $\mathrm{c} 88,52$ & 78,53 \\
\hline Média & 68,79 & 77,47 & 88,19 & \\
\hline \multicolumn{5}{|c|}{ Valores de CUC (\%) para 2 linhas radiais } \\
\hline 2,5 & a75,57 & $\mathrm{b} 83,21$ & c90,61 & 83,13 \\
\hline 5 & a74,98 & $\mathrm{b} 82,11$ & $\mathrm{c} 90,08$ & 82,39 \\
\hline 7,5 & a76,06 & b81,57 & $\mathrm{c} 90,13$ & 82,59 \\
\hline 10 & a73,92 & b81,63 & $\mathrm{c} 89,61$ & 81,72 \\
\hline 12,5 & a75,03 & $\mathrm{b} 82,20$ & $\mathrm{c} 90,31$ & 82,51 \\
\hline Média & 75,11 & 82,14 & 90,15 & \\
\hline \multicolumn{5}{|c|}{ Valores de CUC (\%) para 3 linhas radiais } \\
\hline 2,5 & a79,03 & $\mathrm{b} 85,29$ & c91,52 & 85,28 \\
\hline 5 & a78,47 & $\mathrm{b} 84,14$ & c91,09 & 84,57 \\
\hline 7,5 & a79,67 & $\mathrm{b} 83,30$ & c91,10 & 84,69 \\
\hline 10 & a77, 18 & $\mathrm{~b} 83,70$ & c90,54 & 83,81 \\
\hline 12,5 & a78,14 & b84,54 & c91,16 & 84,61 \\
\hline Média & 78,50 & 84,19 & 91,08 & \\
\hline \multicolumn{5}{|c|}{ Valores de CUC $(\%)$ para 4 linhas radiais } \\
\hline 2,5 & $\mathrm{a} 81,08$ & $\mathrm{ab86,68}$ & b91,95 & 86,57 \\
\hline 5 & $a 80,53$ & $\mathrm{~b} 85,40$ & b91,43 & 85,79 \\
\hline 7,5 & a81,56 & $\mathrm{b} 84,51$ & b91,58 & 85,88 \\
\hline 10 & a79,40 & $\mathrm{ab} 84,97$ & b91,02 & 85,13 \\
\hline 12,5 & a79,75 & a85,93 & a91,51 & 85,73 \\
\hline Média & 80,46 & 85,50 & 91,50 & \\
\hline
\end{tabular}

1 - Médias seguidas por letras distintas, na horizontal, diferem estatisticamente entre si, no nivel de $5 \%$ (Tukey). 


\subsection{2 - Quatro Linhas Radiais}

Pelo teste de Tukey, no nível de probabilidade de $5 \%$, os valores de CUC diferiram entre si, nos espaçamentos de $2,5 \mathrm{~m}$ e $10,0 \mathrm{~m}$ entre coletores, para as alturas de $1,10 \mathrm{~m}$ e 3,20 $\mathrm{m}$ dos emissores em relação à superfície de captação dos coletores. Nos espaçamentos de 5,0 m e 7,5 m, os valores de CUC diferiram somente à altura de $1,10 \mathrm{~m}$. No espaçamento de $12,5 \mathrm{~m}$ entre coletores, os valores de CUC não diferiram estatisticamente, nas três alturas. Esse resultado não seguiu os apresentados por 1, 2 e 3 linhas radiais (Quadro 8). A Figura 18 (d), que representa graficamente os dados do Quadro 8, ilustra o aumento nos valores de CUC, em função do aumento da altura dos emissores. Os maiores valores de CUC são observados à altura de 3,20 m dos emissores, em relação à seção de captação dos coletores.

\subsection{3 - Comparação entre as quatro linhas radiais}

Os valores de CUC aumentaram, em função de 1, 2, 3 ou 4 linhas radiais, e também do aumento na altura dos emissores (Quadro 8). Os menores valores de CUC são encontrados na menor altura dos emissores $(1,10 \mathrm{~m})$. Isso acontece porque não há um recobrimento adequado dos jatos de água dos emissores devido ao espaçamento entre os emissores $(2,13 \mathrm{~m})$ não ser adequado para essa altura dos emissores em relação à seção de captação dos coletores. Os testes realizados nessa altura ( $1 \mathrm{~A}$ e $1 \mathrm{~B})$ apresentaram o menor diâmetro molhado (Quadro 3).

As Figuras 7 e 8, representando os emissores à altura de 3,20 m, apresentam os menores valores de desvio padrão. Isso leva à conclusão de que, com o aumento na altura dos emissores, ocorre uma melhora na uniformidade de distribuição da água, reduzindo os valores do desvio-padrão.

Os valores de CUC, com o aumento na altura dos emissores, apresentam menor variação na mudança de 1 para 2, 3 e 4 linhas radiais (Quadro 7 e Figura 16). 
A Figura 18 ilustra que com o aumento do número de linhas radiais, num mesmo espaçamento entre os coletores, nas três alturas dos emissores, os valores de CUC tendem a se aproximar.

Os resultados encontrados são compatíveis com aqueles apresentados por James \& Blair (1984), Furukawa (1991), Teixeira (1992), Denículi et al. (1993) e Miranda et al. (1994).
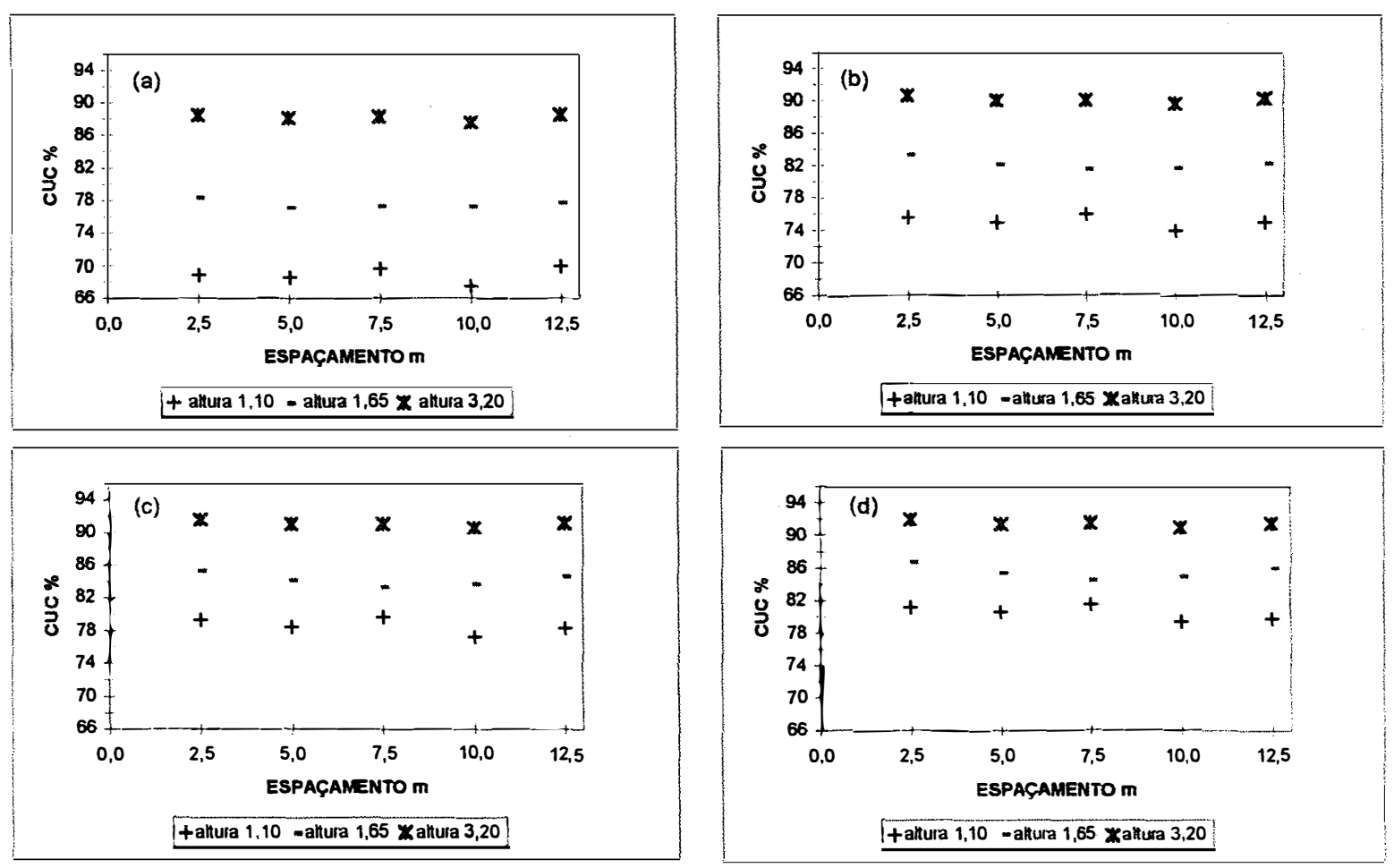

Figura 18 - Valores de CUC, em cinco espaçamentos diferentes entre os coletores e a três alturas diferentes dos emissores para 1 (a), 2 (b), 3 (c) e 4 (d) linhas radiais.

\section{4 - ANÁLISE DE REgressões}

\subsection{1 - Número de Linhas Radiais e Espaçamento entre os Coletores}

As equações para estimativa do CUC, em função do número de linhas radiais e do espaçamento entre os coletores, para os emissores a $1,10 \mathrm{~m}, 1,65 \mathrm{~m} \mathrm{e} 3,20 \mathrm{~m}$ em relação à seção de captação dos coletores, são apresentadas a seguir: 
Emissor a $1,10 \mathrm{~m}$

$$
\mathrm{CUC}=60,51+9,64 \mathrm{NL}-1,09 \mathrm{NL}^{2}\left(\mathrm{R}^{2}=0,9678\right)
$$

Emissor a $1,65 \mathrm{~m}$

$$
\mathrm{CUC}=74,28+6,88 \mathrm{NL}-0,84 \mathrm{NL}^{2}-0,83 \mathrm{E}+0,05 \mathrm{E}^{2}\left(\mathrm{R}^{2}=0,9891\right)
$$

Emissor a 3,20 m

$$
\mathrm{CUC}=86,52+3,09 \mathrm{NL}-0,39 \mathrm{NL}^{2}-0,30 \mathrm{E}+0,02 \mathrm{E}^{2}\left(\mathrm{R}^{2}=0,9657\right)
$$

em que:

$\mathrm{NL}$ - número de linhas radiais;

E - espaçamento entre os coletores, $\mathrm{m}$.

Através dessas equações, observa-se a influência da altura dos emissores na avaliação desse sistema de irrigação.

Com os emissores a $1,10 \mathrm{~m}$ de altura, a influência da variável espaçamento (E e $\left.\mathrm{E}^{2}\right)$ no CUC não foi significativa, no nivel de probabilidade de $5 \%$, pelo teste $F$. Nessa condição, o equipamento apresentou a pior uniformidade na distribuição da água.

Com os emissores a 1,65 m, a variável espaçamento ( $E$ e $E^{2}$ ) foi significativa, porém apresentou menor influência no CUC, em relação ao número de linhas radiais. Isso pode ser observado nos baixos valores dos coeficientes da variável espaçamento, tanto no efeito linear, como no quadrático. Também, pelos valores dos coeficientes, verifica-se que o efeito do número de linhas laterais foi menor à altura de $1,65 \mathrm{~m} \mathrm{em}$ relação à altura de $1,10 \mathrm{~m}$. Com emissores a $1,65 \mathrm{~m}$, o equipamento apresentou valores de CUC maiores que a $1,10 \mathrm{~m}$ de altura. Devido a tal aumento nos valores de CUC, diminuiu a influência da variável número de linhas $\left(\mathrm{NL} \mathrm{e} \mathrm{NL}^{2}\right)$.

Com os emissores a 3,20 m de altura, os valores dos coeficientes das variáveis número de linhas ( $\mathrm{NL}$ e $\mathrm{NL}^{2}$ ) e espaçamento $\left(\mathrm{E} \mathrm{e}^{2}\right.$ ) diminuíram. Isso ocorre devido ao equipamento, nessa condição, apresentar a melhor uniformidade de distribuição de água, ou seja, os maiores valores de CUC. Nos Quadros 5 e 7, observa-se que, para os emissores a 3,20 m, ocorre a menor variação nos valores de CUC, em função do aumento do espaçamento entre os coletores e do número de linhas radiais. Isso justifica 
a redução nos valores dos coeficientes das variáveis número de linhas $\left(\mathrm{NL}\right.$ e $\left.\mathrm{NL}^{2}\right)$ e espaçamento (E e $\left.E^{2}\right)$.

A interação entre NL.E não foi significativa nas três alturas dos emissores, no nível de probabilidade de $5 \%$, pelo teste $\mathrm{F}$.

\subsection{2 - Espaçamento entre os Coletores e Altura dos Emissores}

As equações para estimativa do CUC, em função do espaçamento entre os coletores e da altura dos emissores para 1, 2, 3 e 4 linhas radiais de coletores, são apresentadas a seguir:

\section{Linha Radial}

$$
\mathrm{CUC}=63,98+0,02 \mathrm{E}^{2}+5,23 \mathrm{~A}+1,08 \mathrm{~A}^{2}\left(\mathrm{R}^{2}=0,9954\right)
$$

2 Linhas Radiais

$$
\mathrm{CUC}=71,57+0,02 \mathrm{E}^{2}+5,01 \mathrm{~A}\left(\mathrm{R}^{2}=0,9928\right)
$$

3 Linhas Radiais

$$
\mathrm{CUC}=76,78+0,02 \mathrm{E}^{2}+3,24 \mathrm{~A}\left(\mathrm{R}^{2}=0,9850\right)
$$

4 Linhas Radias

$$
\mathrm{CUC}=79,37+0,021 \mathrm{E}^{2}+2,83 \mathrm{~A}\left(\mathrm{R}^{2}=0,9817\right)
$$

em que:

A - altura do emissor, $\mathrm{m}$.

Através dessas equações, observa-se a influência do número de linhas radiais na avaliação desse sistema de irrigação. Em função do aumento no número de linhas radiais, ocorre uma diminuição da influência da variável altura dos emissores (A) sobre os valores de CUC. Observa-se isso através da redução no valor do coeficiente da variável $\mathrm{A}$, em função do aumento no número de linhas radiais. 
O coeficiente da variável espaçamento $\left(E^{2}\right)$ não se modifícou em função do aumento do número de linhas radiais, permanecendo com baixo valor nas equações, em relação ao coeficiente da variável altura do emissores $\left(\mathrm{A} \mathrm{e}^{2}\right.$ ).

$\mathrm{A}$ interação entre $\mathrm{A}$ e $\mathrm{E}$ não foi significativa, no nivel de $5 \%$ de probabilidade, pelo teste $F$, para 1, 2, 3 e 4 linhas radiais.

\subsection{3 - Número de Linhas Radiais e Altura dos Emissores}

As equações para estimativa do CUC, em função do número de linhas radiais e da altura dos emissores para os espaçamentos de $2,5 \mathrm{~m}, 5,0 \mathrm{~m}, 7,5 \mathrm{~m}, 10,0 \mathrm{~m}$ e $12,5 \mathrm{~m}$ são apresentadas a seguir:

Espaçamento de $2,5 \mathrm{~m}$ entre os coletores

$\mathrm{CUC}=51,39+9,50 \mathrm{NL}-0,81 \mathrm{NL}^{2}+10,61 \mathrm{~A}-1,42 \mathrm{~A} . \mathrm{NL}$

$\left(\mathrm{R}^{2}=0,9949\right)$

Espaçamento de 5,0 m entre os coletores

$\mathrm{CUC}=53,03+9,46 \mathrm{NL}-0,81 \mathrm{NL}^{2}+7,84 \mathrm{~A}+0,74 \mathrm{~A}^{2}-1,42 \mathrm{~A} . \mathrm{NL}$

$\left(\mathrm{R}^{2}=0,9949\right)$

Espaçamento de 7,5 m entre os coletores

$\mathrm{CUC}=57,88+9,30 \mathrm{NL}-0,78 \mathrm{NL}^{2}+3,21 \mathrm{~A}+1,81 \mathrm{~A}^{2}-1,46 \mathrm{~A} . \mathrm{NL}$

$\left(\mathrm{R}^{2}=0,9931\right)$

Espaçamento de 10,0 m entre os coletores

$\mathrm{CUC}=50,63+9,02 \mathrm{NL}-0,75 \mathrm{NL}^{2}+10,15 \mathrm{~A}-1,39 \mathrm{~A} . \mathrm{NL}$

$\left(\mathrm{R}^{2}=0,9960\right)$

Espaçamento de 12,5 m entre os coletores

$\mathrm{CUC}=53,90+8,37 \mathrm{NL}-0,72 \mathrm{NL}^{2}+8,72 \mathrm{~A}-1,21 \mathrm{~A} \cdot \mathrm{NL}$

$\left(\mathrm{R}^{2}=0,9934\right)$ 
Através dessas equações observa-se pequena influência do espaçamento entre os coletores sobre os valores do CUC desse sistema de irrigação.

Os coeficientes das variáveis NL, A e NL.A praticamente não se alteraram, em função do aumento no espaçamento entre os coletores. A Figura 17 também demonstra a pequena influência do espaçamento entre os coletores sobre o valor de CUC, para esse sistema de irrigação. 


\section{5 - CONCLUSÕES}

a) Não houve efeito significativo dos espaçamentos entre coletores sobre o coeficiente de uniformidade de Christiansen.

b) A utilização de duas linhas radiais constituiu a melhor condição para a determinação do coeficiente de uniformidade de Christiansen.

c) A altura dos emissores apresentou efeito significativo sobre o coeficiente de uniformidade de Christiansen. 


\section{REFERÊNCIAS BIBLIOGRÁFICAS}

ABO-GHOBAR, H. M. Losses from low-pressure center-pivot irrigation systems in a desert climate as affected by nozzle height. Agriculture and Water Management, v. 21, n. 1/2, p. 23-32, June 1992.

ALI ARSHAD, S. M.; BAREFOOT, A. D. Performance of center pivot sprinkler irrigation systems opering at reduced pressures. St. Joseph: ASAE, 1978. 19 p. (ASAE Paper, 78-2005)

AMERICAN SOCIETY OF AGRICULTURAL ENGINEERS. ASAE standards. $38^{\circ}$ ed. St. Joseph, 1991. p. 653-4: Test procedure for determining the uniformity of water distribution of center pivot, corner pivot and moving lateral irrigation machines equipped with spray or sprinkler nozzles: S436.

ASSOCIAÇÃO BRASILEIRA DE NORMAS TÉCNICAS. Sistema de irrigação por aspersão pivô central: caracterização de desempenho/método de ensaio. Rio de Janeiro, 1985. 22 p. (Projeto de norma, 12:02.08-005).

BEN-ASHER, J.; AYARS, J. E. Deep seepage under nonuniform sprinkler irrigation. I. Theory. Journal of Irrigation and Drainage ASCE, v. 116, n. 3, p. 354-62, May/June 1990.

BERNARDO, S. Manual da irrigação. 5. ed. Viçosa: Imprensa Universitária, 1989. $596 \mathrm{p}$.

BREMOND, B.; MOLLE, B. Characterization of rainfall under center pivot: influence of measuring procedure. Journal of Irrigation and Drainage Engineering, v. 121, n. 5, p. 347-53, Sept./Oct. 1995.

BRIDE, S. Análise de uniformidade da distribuição de água em sistema de irrigação por pivô central. Viçosa, 1984. 87 p. Dissertação (M.S.) - Universidade Federal de Viçosa.

CHRISTIANSEN, J. E. Irrigation by sprinkling. Berkeley: University of California, California Agricultural Experiment Station, 1942. 124 p. (Bulletin n. 670). 
COELHO, R. D. Regulagens de aspersores e seus efeitos sobre a uniformidade de aplicação de água e produtividade das culturas. Piracicaba, 1990. 141 p. Dissertação (Mestrado) - Escola Superior de Agricultura "Luiz de Queiroz", Universidade de São Paulo.

CUENCA, R. H. Irrigation system design: an engineering approach. Englewood Clifs: Prentice-Hall, 1989. $551 \mathrm{p}$.

D'ASSUNPÇÃO, A. L. G. Efeito do espaçamento entre coletores e da velocidade de operação na avaliação de um sistema pivô central. Fortaleza, 1990. 135 p. Dissertação (Mestrado) - Universidade Federal do Ceará.

DAKER, A. Á água na agricultura: irrigação e drenagem. 6. ed. Rio de Janeiro: Freitas Bastos, 1984. 543 p.

DAVIS, J. R. Measuring water distribution from sprinklers. Transaction of the ASAE, v. 9 , n. 1, p. $94-7,1966$.

DENICULI, W.; ITABORAHY, C. R.; LOUREIRO, B. T.; RAMOS, M. M. Uniformidade de aplicação de água em sistema de irrigação por aspersão com deslocamento contínuo equipados com tubos de descida flexíveis. In: CONGRESSO BRASILEIRO DE ENGENHARIA AGRÍCOLA, 22., Ilheus, 1993. Anais. Ilheus: SBEA, 1993. p. 2787-801.

DUKE, H. R.; HEERMANN, D. F.; DAWSON, L. J. Appropriate depths of application for scheduling center pivot irrigations. Transactions of the ASAE, v. 35, n. $5, \mathrm{p}$. 1457-64, Sept./Oct. 1992.

FRIZZONE, J. A. Irrigação por aspersão: uniformidade e eficiência. Piracicaba: ESALQ, Dept. Eng. Rural, 1992. 53 p. (Série Didática, 3).

FURUKAWA, C. Avaliação da irrigação por pivô central na região de Rio Verde - GO., Viçosa, 1991. 69 p. Dissertação (Mestrado) - Universidade Federal de Viçosa.

HANSON, B. R.; LANCASTER, D. L. Some causes of nonuniformity are correctable. California Agriculture, v. 40, n. 5/6, p. 24-6, May/June 1986.

HANSON, B.R.; WALLENDER, W.W. Bidirectional uniformity of water applied by continuos-move sprinkler machines. Transaction of the ASAE, v. 29, n. 4, p. 1047-53, July/Aug. 1986. 
HEERMANN, D. F. Center pivot design and evaluation. In: NATIONAL. IRRIGATION SYMPOSIUM, 3., Phoenix, 1990. Procedings. St. Joseph: ASAE, 1990. p. 564-9.

HEERMANN, D. F.; HEIN, P. R. Performance characteristics of self- propelled centerpivot sprinkler irrigation system. Transaction of the ASAE, v. 11, n. 1, p. 11-5, 1968.

HEERMANN, D.F.; WALLENDER, W.W.;BOS, M.G.; Irrigation efficiency and uniformity. In: HOFFMAN, G.J.; HOWELL, T.A.; SOLOMON, K.H. Management of farm irrigation systems St. Joseph: ASAE, 1990. cap. 6, p. 12546.

HEINEMANN, A. B.; FRIZZONE, J. A. Custo da melhora da uniformidade de distribuição de água por um pivô central vs. economia de energia. In: CONGRESSO BRASILEIRO DE ENGENHARIA AGRÍCOLA, 24., Viçosa, 1995. Anais. Viçosa: SBEA, 1995. p. 189 .

HOFFMAN, G. J.; MARTIN, D. L. Engineering systems to enhance irrigation perfomance. Irrigation Science, v. 14, n. 2, p. 53-63, Apr. 1993.

HUNSAKER, D. J.; BUCKS, D. A. Wheat yield variability in irrigated level basins. Transactions of the ASAE, v. 30, n. 4, p. 1099-104, July 1987.

JAMES, L. G.; BLAIR, S. K. Performance of low pressure center-pivot systems. Transactions of the ASAE, v. 27, n. 6, p. 1753-57, Nov. 1984.

KLAR, E.A. Irrigação: frequência e quantidade de aplicação. São Paulo: Nobel, 1991. p. 156.

LETEY, J. Irrigation uniformity as related to optimum crop production - additional research is needed. Irrigation Science, v. 6, n. 4, p. 253-63, Oct. 1985.

LONGO, L. A. Uniformidade de distribuição e eficiência, em potêncial, de aplicação de água de um pivô central, equipados com tubo de descida. Viçosa, 1991. 63 p. Dissertação (Mestrado) - Universidade Federal de Viçosa.

MAREK, T. U.; UNDERSANDER, D. J.; EBELING, L. L. An areal weighted uniformity coefficient for center pivot irrigations systems. Transaction of the ASAE, v. 29, n. 6, p. 1665-7, Nov./Dec., 1986. 
MERRIAM, J. L.; KELLER, J. Farm irrigation systens evaluation: a guide for management. 3. ed. Logan: Utah State University, 1978. 285 p.

MIRANDA, F. R. de; RAMOS, M. M.; DENÍCULI, W.; SOARES, A. A. Uniformidade de distribuição de água de um sistema de irrigação, do tipo linear e de baixa pressão, em função da altura de instalação e do tipo de placa defletora. In: CONGRESSO BRASILEIRO DE ENGENHARIA AGRÍCOLA, 22., Campinas, 1994. Anais. Campinas: SBEA, 1994. p. 1-8.

PAIR, C. H. Water distribution under sprinkler irrigation. Transaction of the ASAE, v. 11, n. 5, p. 648-51, 1968.

PAZ, V. P. S. da. Condições ótimas de operação de sistemas de irrigação por aspersão. Piracicaba, 1995. 125 p. Tese (Doutorado) - Escola Superior de Agricultura "Luiz de Queiroz", Universidade de São Paulo.

RAMOS, M. M.; MANTOVANI, E. C. Sistemas de irrigação e seus componentes. In: COSTA, E. F.; VIEIRA, R. F.; VIANA, P. A. Quimigação: aplicação de produtos químicos e biológicos via irrigação. Brasilia: EMBRAPA, 1994. cap. 2, p. 41-82.

RAPP, E.; CHANASYK, D. S.; HORVATH, B. C. Simulated model of center pivot sprinkler irrigation systems. Canadian Agricultural Engineering, v. 2, n. 21, p. 141-5, Dec. 1979.

RESENDE, R. Desempenho de um sistema de irrigação pivô central quanto a uniformidade e eficiência de aplicação de água, abaixo e acima da superficie do solo. Piracicaba, 1992. 79 p. Dissertação (Mestrado) - Escola Superior de Agricultura "Luiz de Queiroz", Universidade de São Paulo.

SCALOPPI, E. J. Critérios básicos para seleção de sistemas de irrigação. Informe Agropecuário, v. 12, n. 139, p. 54-63, Jul. 1986.

SCALOPPI, E. J. Eficiência de aplicação da água em sistemas de irrigação por aspersão. ITEM Irrigação e Tecnologia Moderna, n. 16, p. 37-40, Mar. 1984.

SILVA, W. L. C. Considerações sobre o uso de "sprays"de baixa pressão em pivô central. ITEM Irrigação e Tecnologia Moderna, n. 39, p. 26-72, 1989.

SOLOMON, K. H. Yield related interpretations of irrigation uniformity and efficiency measures. Irrigation Science, v. 5, n. 3, p. 161-72, July 1984. 
TEIXEIRA, A. S. dos. Estudo do efeito de diferentes tipos de emissores na performance de um sistema de irrigação por aspersão pivô central. Piracicaba, 1992.79 p. Dissertação (Mestrado) - Escola Superior de Agricultura "Luiz de Queiroz", Universidade de São Paulo.

THOOYAMANI, K. P.; NORUM, D. I.; DUBETZ, S. Application rates and uniformity under center-pivot sprinkler irrigation systens using spray nozzles. Canadian Agricultural Engineering, v. 2, n. 29, p. 149-57, 1987.

VIEIRA, R. F. Introdução a quimigação. In.: COSTA, E. F.; VIEIRA, R. F.; VIANA, P. A. Quimigação: aplicação de produtos químicos e biológicos via irrigação. Brasília: EMBRAPA, 1994. cap. 1, p. 13-30. 